\title{
ON DEMAND: CROSS-COUNTRY EVIDENCE FROM COMMERCIAL REAL ESTATE ASSET MARKETS
}

\author{
Steven H. Ott \\ Belk College of Business and Administration, University of North Carolina - Charlotte, \\ shott@uncc.edu
}

\section{Timothy J. Riddiough}

School of Business, University of Wisconsin - Madison, triddiough@bus.wisc.edu

\section{Ha-Chin Yi}

McCoy College of Business Administration, Texas State University - San Marcos, hy11@txstate.edu

\section{Jiro Yoshida}

Department of Economics, Tokyo University, Jiro@e.u-Tokyo.ac.jp

\begin{abstract}
Using over 25 years of quarterly U.S. and Japanese time series data, this paper examines the determinants of demand for an important class of real assets: commercial real estate. We specify a structural model of market equilibrium that considers direct effects of real investment on built asset price. Our empirical findings are consistent across countries and produce several new results. First, we find that real investment exerts a significant positive direct effect on asset price, which in turn feeds back to impact investment decisions. Second, idiosyncratic risk is found to be strongly positively related to asset price, and to complement supply effects. Third, systematic risk is priced as expected, where the strength of the relation between asset price and systematic risk is found to be higher than in previous studies of capital asset prices. Fourth, lagged values of price determinants (of up to two years) are consistently important in real asset demand estimation. Alternative explanations for our findings are analyzed and discussed. Implications for asset pricing model specification and interpretation are also considered.
\end{abstract}




\section{Keywords}

Investment; asset pricing; momentum effects; real estate

\section{Introduction}

Secondary markets for real assets differ from financial asset markets in several important ways. Real asset markets tend to be decentralized search markets as opposed to centralized exchange-traded markets (Wheaton, 1990; Williams, 1995). Incomplete information and costly information acquisition are therefore central to the price discovery process. Investors in real asset markets are also often capital constrained and under diversified, resulting in an important role for outside finance. Duality - the existence of simultaneous economic and asset markets for an underlying product - make the structure of real asset markets directly relevant to investors. For example, commercial property markets are characterized by the coexistence of a market for space consumption and an investment market for built assets, which interact to determine equilibrium rent levels, capitalized asset prices and the rate of new development. It is commonly thought that these characteristics decentralized markets, information frictions, investor specialization and reliance on outside capital, and duality - have historically produced highly cyclical markets for certain durable economic goods.

Differences in markets for real assets suggest a different approach to their valuation. However, with a few important exceptions (see Williams, 1993, 1995), very little research has addressed the pricing of real assets on their own terms as opposed to simply applying conventional models of exchange-traded financial asset price. Indeed, we are unaware of any model that might be referred to as a "real" capital asset pricing model. We address this gap in the literature by empirically examining the demand for an important class of real assets: commercial real estate. To do this we specify a structural model of real asset demand that incorporates not only space market (rental) and financial market effects, but also considers a direct role for real investment on asset price. Supply (real investment) and demand (asset price) are thus determined simultaneously in asset market equilibrium, where other price determinants include rent, interest rate, income growth rate, systematic risk and total uncertainty.

Data used to estimate our model are over 25 years of quarterly time series data spanning from the early 1970's to the late 1990's - from US and Japanese property and financial asset markets. The property data are aggregate both geographically and by use (e.g., office versus retail). Even though these two (very large) markets for commercial real estate differ significantly in numerous respects, our estimation results are remarkably consistent across countries. Most importantly, we find that real investment exerts a statistically and economically significant positive direct effect on asset price. Positive feedback thus exists between asset price and new investment, providing insight into long-standing empirical puzzles such as why price-earnings ratios in many real asset markets move directly as opposed inversely 
with the supply cycle. Causes for this outcome are explored, including the possibility that a positive relation between asset price and supply is a complementarily-induced elasticity effect (Rauch, 1993). We also consider information-based explanations, including the development bandwagon approach of Grenadier (1999) and the financial institutional beauty contest approach of Scharfstein and Stein (1990).

Systematic risk and total uncertainty are also important determinants of real asset price in our model estimations. (Merton, 1973, 1990) suggests that second moments of the return distribution may be more important than first moments when innovations to the investment opportunity set occur frequently over time. As a result we include both of these risk measures as inputs to the model, as opposed to estimating them within the model. Consistent with expectations, systematic risk is found to exert a statistically significant negative effect on asset price. Contrary to expectations, we find that total uncertainty is positively related to asset price, and that the intensity of the total uncertainty-asset price relation increases when the supply variable is allowed to enter into the demand equation. Several possible explanations for this latter finding are explored, including long-run rent signaling, growth option value increases, and the possibility that increases in the rate of information arrival reduce information disparity in real asset markets.

Current, lagged and possibly lead values of the explanatory variables are also considered in model estimation. Several disparate strands of the literature, including intertemporal asset pricing with shifting investment opportunities (e.g., Merton, 1973), market microstructure which emphasizes market imperfections and trading rules (e.g., O'Hara, 1997) and complementarities in macroeconomics that result in positive payoff externalities (Cooper, 1999), suggest that time series paths of prices and price determinants are potentially informative to investors. We indeed find that the structure of lagged explanatory values are important to investors, where historical values of up to two years are included in the final model estimations.

Other findings are generally as expected. The rent variable, as determined in space market equilibrium, exerts a positive and typically statistically significant effect on asset price. This effect is found to be stronger in the Japanese data than in the U.S. data, which may be due to differences in lease contract structure and tenant retention. The effect of the real rate of interest on real asset price is negative but is not consistently statistically significant. Optionality in real asset value, the periodic delinking of interest rate and asset price (especially in Japan) and maturity mismatches in asset cash flow and bond duration may underlie this result. Expected growth rate in income, as proxied with the growth rate in GDP, is found to be the weakest of demand determinants.

Our findings suggest that real asset pricing differs in several important ways from conventional financial asset pricing. Information and structural market effects are found to be central to asset demand determination. Indeed, market structure is directly relevant to the asset price discovery process, as new investment provides an information path to investors that are independent of other price determinants. 
Furthermore, interactions between total uncertainty and supply are found to intensify positive feedback between supply and demand, which together goes a long way in explaining boom and bust in real asset markets. Finally, a significant lag structure in asset price estimation provides support for alternative theories of asset prices that emphasize dynamic change and complex interactions between demand determinants.

Our results also have structural implications for models of real asset market equilibrium that focus on supply response. Because real asset market demand may be directly sensitive to new investment, one cannot simply posit a dynamically nonintegrative price-investment relation on the demand side of the market and then estimate a supply under the presumption that asset price is exogenously determined.

The main body of the paper is organized as follows. In section II we specify two structural models of real asset demand and discuss the data used to estimate our models. Real asset demand model specification and estimation are also contrasted with conventional empirical approaches to financial asset pricing model specification and estimation. Estimation results are reported and analyzed in section III. U.S. estimates are presented first, and then are compared and contrasted with Japanese results. Section IV summarizes our findings and concludes the paper.

\section{Economic Setting, Model Specification and Data}

\subsection{Economic Setting and Model Specification}

In our analysis we will examine the structural role of net income and financial market variables in the determination of demand for durable real assets. We will also consider the possibility that supply has a direct effect on real asset price.

Direct supply effects are considered for several reasons. First, financial asset pricing theory typically posits infinitely elastic asset demand. This specification makes sense for financial assets that are actively traded in centralized exchange markets in which information is cheaply available and for which numerous close substitutes exist. Real asset markets such as commercial real estate generally do not conform to these characteristics: assets are heterogeneous and therefore are not perfectly substitutable, and they are traded in local decentralized markets in which information is costly and asymmetries are common. Moreover, investors are often capital constrained and underdiversifed. Spillovers are also commonplace, with both positive (e.g., agglomeration) and negative (e.g., congestion) effects resulting from new supply.

Second, market imperfections may result in model specification problems that can be addressed by incorporating supply-side information. For example, commercial real estate leasing contracts typically range from one to ten years in many countries, including the U.S. and Japan. Thus there does not exist an entire term structure of lease contract rates that fully incorporate supply effects. Furthermore, a futures or options market to trade on forward rental rates is also non-existent. Supply changes 
may therefore provide valuable information regarding medium to long-term expected cash flows that are relevant in the determination of asset price.

Third, in a noisy rational expectations setting with a given asset trading structure, measures of trading volume may be useful in sorting out information effects from liquidity and other pertinent effects in the price discovery process. For example, Diamond and Verrecchia (1987) and Easley and O'Hara (1992) consider the consequences of short-sale constraints on asset price and volume. They show that the inability to short sell may induce a strong positive correlation between price and volume, and that the absence of trade signals the existence of new (negative) information that may be useful to investors. Unexpected changes in real investment may provide similar information in decentralized, non-dealer intermediated durable asset markets (Grenadier, 1999). Indeed, the combination of supply variables with more traditional pricing factors may be complementary in the sense that they interact to facilitate the price discovery process.

This analysis suggests that asset demand model specification allow for direct supply-side effects. As a consequence, we specify two distinct models of asset market equilibrium. The first model excludes new construction under the presumption that asset price is the cause of real investment, not the consequence of it. That is, in both models, incentives to undertake development depend on built asset prices. New supply then channels through to the economic (space) market to determine an equilibrium rent level, which is a sufficient statistic that fully summarizes economic market effects as they determine asset price (see DiPasquale and Wheaton, 1996). Our second model places no a priori restrictions on the structure of real asset market equilibrium. In this model supply and demand are determined simultaneously, thus allowing for the possibility that additions to supply exert a rent-independent effect on the demand for real assets.

The two models of the real asset demand are described in equations (1) and (2):

\section{Model 1}

$P=f_{D}\left(R, r, g_{i} \sigma_{P, M}, \sigma\right)$

$$
\begin{aligned}
& \text { Model } 2 \\
& P=f_{D}\left(R, r, g, \sigma_{P, M}, \sigma_{a} C\right) \\
& C=f_{S}\left(P, K, r, g, \sigma_{P, M}, \sigma\right)
\end{aligned}
$$

In both models built asset price $(P)$ depends on capitalized net income (or rent) level, $R$, in which the rental income capitalization rate is a function of the risk-free rate of interest $(r)$, the expected rental growth rate $(g)$, and a risk premium to the risk-free rate as determined in general capital asset market equilibrium $\left(\sigma_{P, M}\right)$. We also include total uncertainty with respect to built asset returns $(\sigma)$ in both specifications. Property owners are often capital constrained and specialized, in the sense that they tie up large portions of their personal wealth in their businesses. This suggests that marginal investors may be less than fully diversified, and as a result 
incorporate idiosyncratic risk into their determination of asset price (see Merton, 1969 for the seminal work on this issue; for a more recent treatment see Heaton and Lucas, 2000). A rather different rationale for inclusion of total uncertainty follows from the option-based model of investment. This model suggests that redevelopment option values may be embedded in the asset price, hence making idiosyncratic risk relevant to investors (see, e.g., Childs et al., 1996; and Williams, 1997).

In model 2 asset price and real investment are determined simultaneously in asset market equilibrium. ${ }^{1}$ The supply equation (2b) describes the behavior of the real estate developer. Asset price determines the slope of the supply curve. Neoclassical models of investment suggest that asset price and construction cost $(K)$ fully identify systematic developer behavior (e.g., Jorgensen 1963; and Tobin 1969). Interest rate, expected rental growth, systematic risk and total asset price uncertainty are traditionally modeled as being embedded in built asset price, and therefore are often omitted in supply equation specifications (see, e.g., Wheaton 1987; Wheaton and Torto 1990 for applications to commercial real estate). In contrast, we include explicit measures of these variables in our specification, as Holland et al. (2000) and Yoshida (1999) provide evidence that these variables exert a price-independent effect on irreversible investment vis-à-vis the option value of delay.

The structural demand equation (2a) depends on new construction as determined endogenously in (2b), plus other explanatory variables. Note that construction cost $(K)$ is excluded from the demand equation and that net rent $(R)$ is excluded from the supply equation. Space markets are competitive in the sense that individual asset owners typically do not possess the market power to directly alter built asset price relative to cost. Expected rent level is clearly a determinant of built asset value, but is generally thought not to exert a supply effect that is independent of asset price.

\subsection{Data Description and Anticipated Price Effects}

We undertake a cross-country comparison of U.S. and Japanese commercial real estate asset markets to assess the robustness of the empirical findings as well as to identify and isolate cross-country differences that may be useful in explaining our findings. As a means to that end, a time series of aggregate economic and financial variables are used to estimate models 1 and 2. Mayer and Somerville (2000) find that, although property markets are often considered localized in scope, there are actually important systematic factors that effectively "nationalize" property markets and therefore reduce bias that can occur when employing aggregate data. Quarterly observations are employed in model estimation, spanning from 1972:1 to 1998:4 in the U.S. data and from 1973:1 to 1998:4 in the Japanese data.

\footnotetext{
${ }^{1}$ New construction is used to represent the short-run inverse supply curve, as opposed the total stock of space. Because commercial real estate is highly durable with a low and predictable rate of economic depreciation, and because of its low marginal cost of operation which rarely results in the mothballing or abandonment of existing space, new construction is a reasonably accurate description of periodic variation in the stock of space.
} 
On Demand: Cross-Country Evidence from Commercial Real Estate Asset Markets 7

Figure 1Time-Series Graphs of the Log of Real Asset Prices: U.S. and Japan U.S. Data

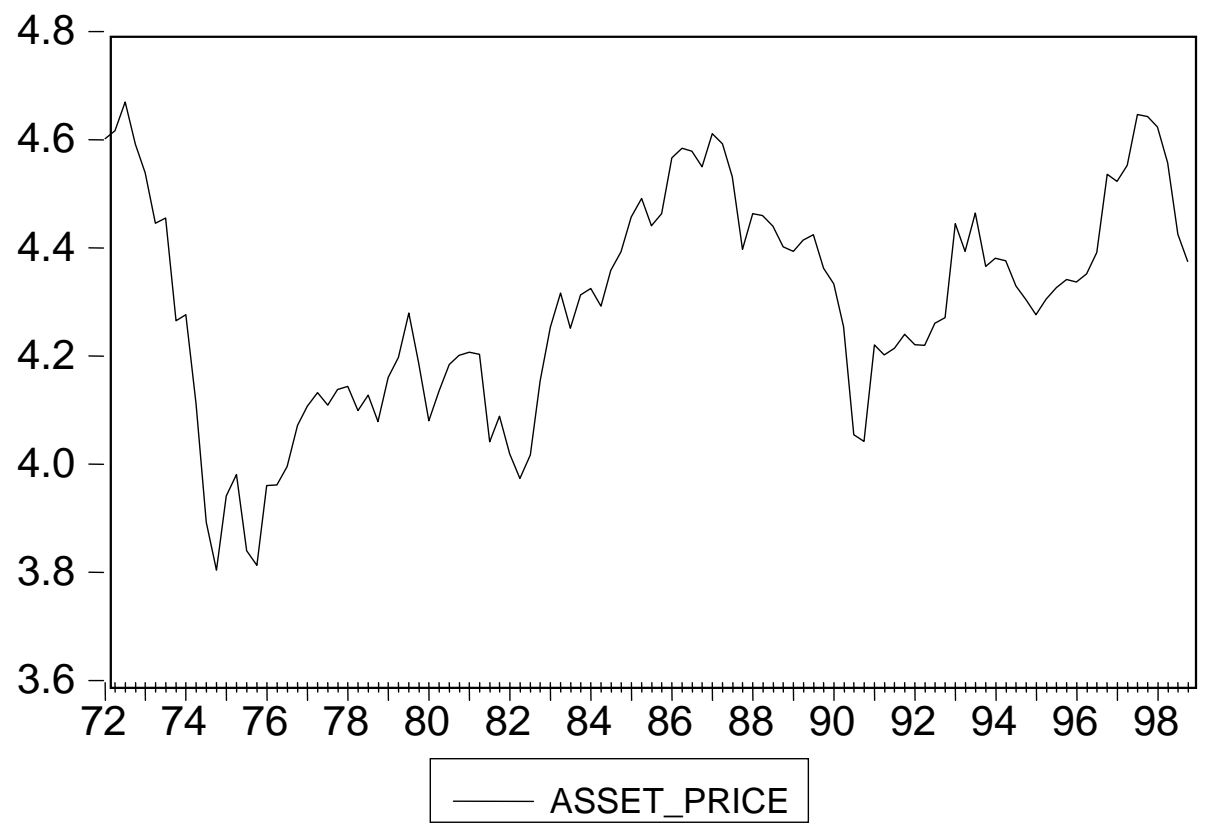

Japanese Data

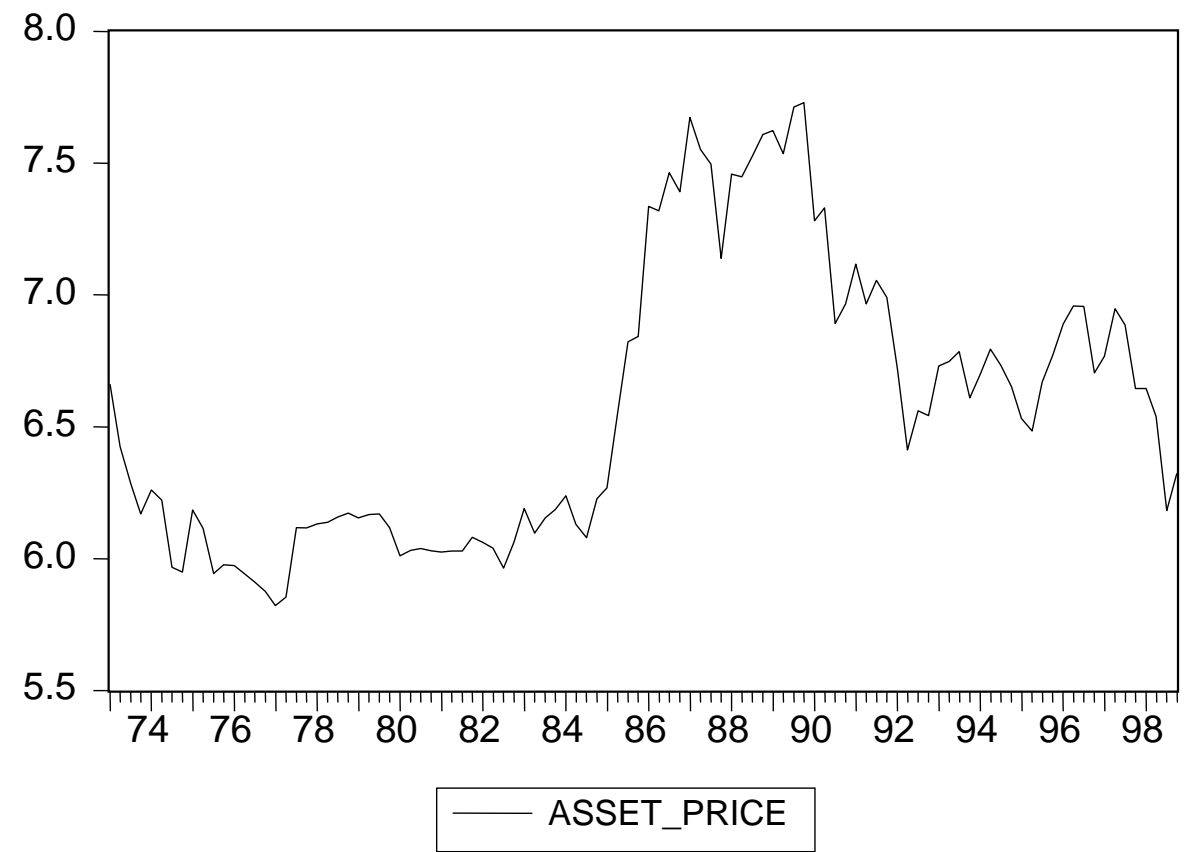


Relevant variables are defined and discussed below. To begin to develop a sense of the data, the asset price time series (in $\log$ ) for both the U.S. and Japan are displayed in Figure 1. The time series of exogenous demand equation variables are also plotted against asset price, as seen in Figures 2 and 3, respectively. Note that, because asset demand model 2 allows for endogenous supply effects, all nominal values are converted to real values.

Figure2 Time-Series Graphs of (Transformed) Demand Determinants as Compared to Real Asset Price: U.S. Data

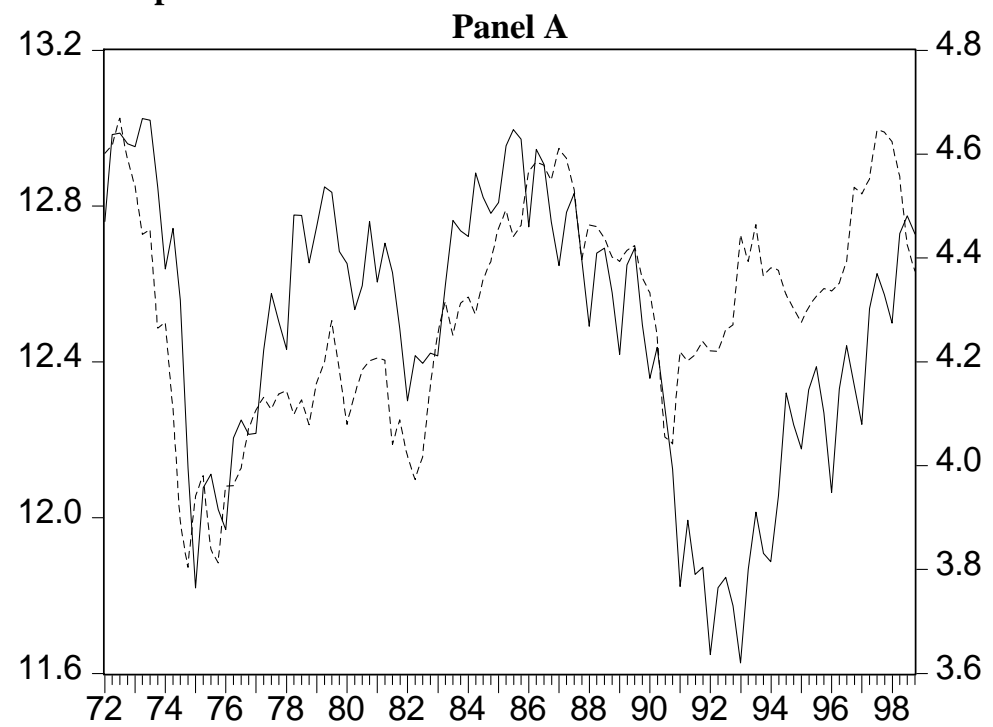

\section{— NEW_CONSTRUCTION ---- ASSET_PRICE}

\section{Panel B}

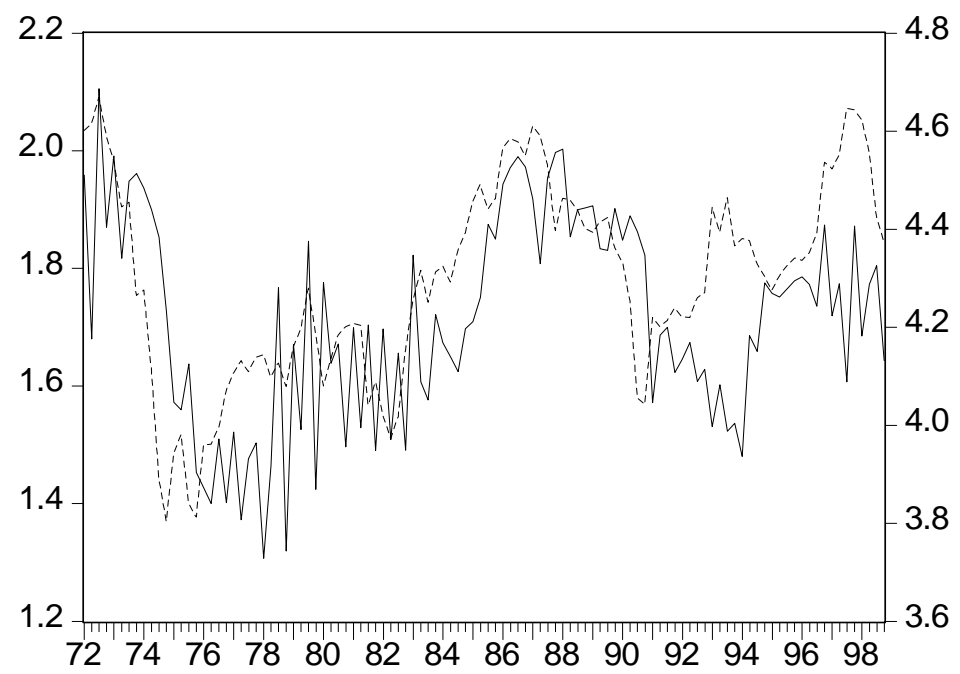


On Demand: Cross-Country Evidence from Commercial Real Estate Asset Markets 9

\section{Panel C}

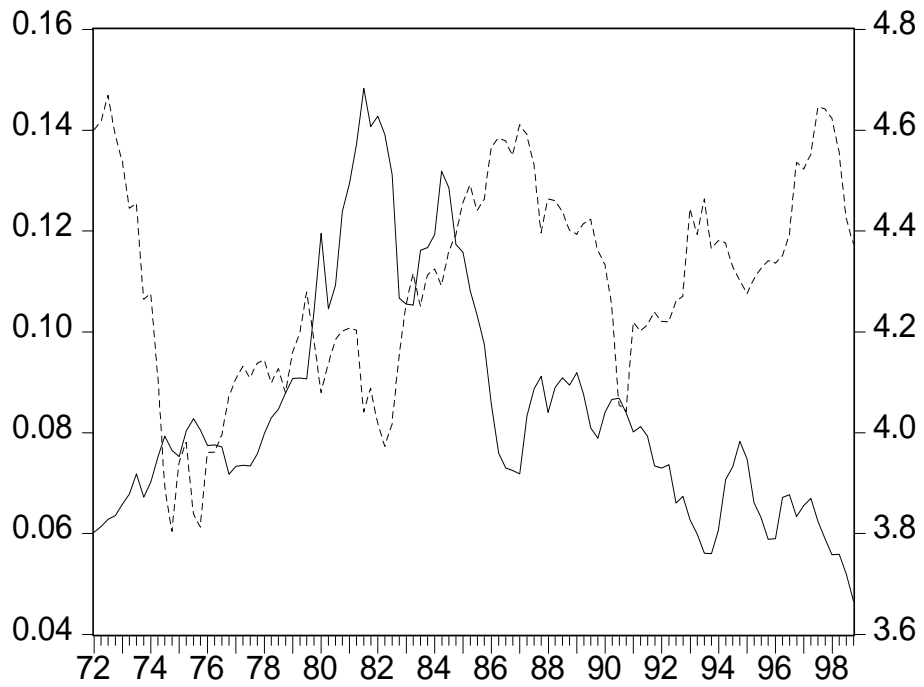

— INTEREST_RATE ----- ASSET_PRICE

\section{Panel D}

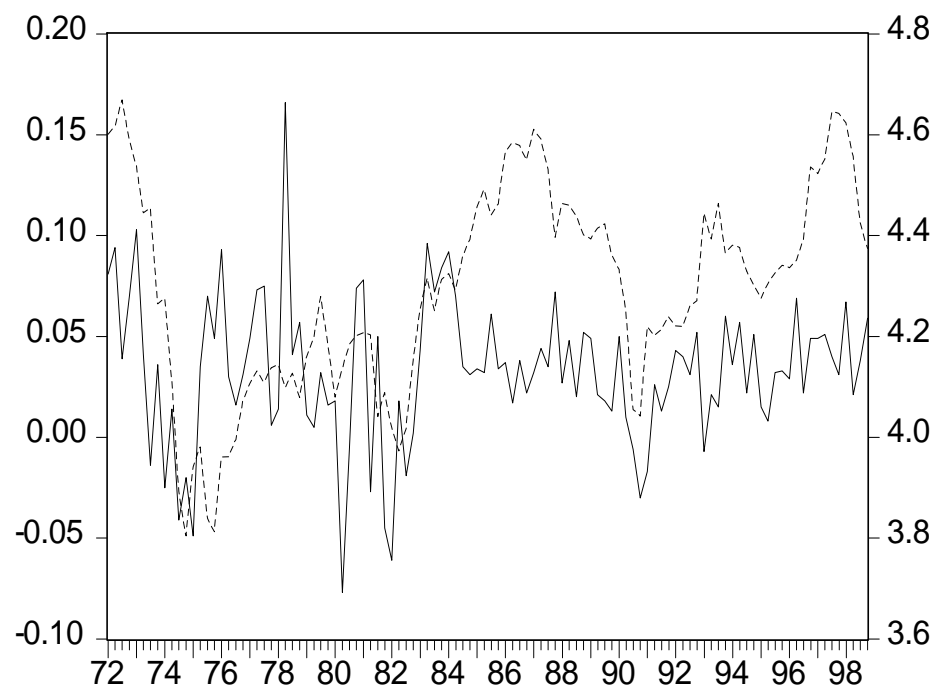

RENT_GROWTH -..- ASSET_PRICE 
Panel E

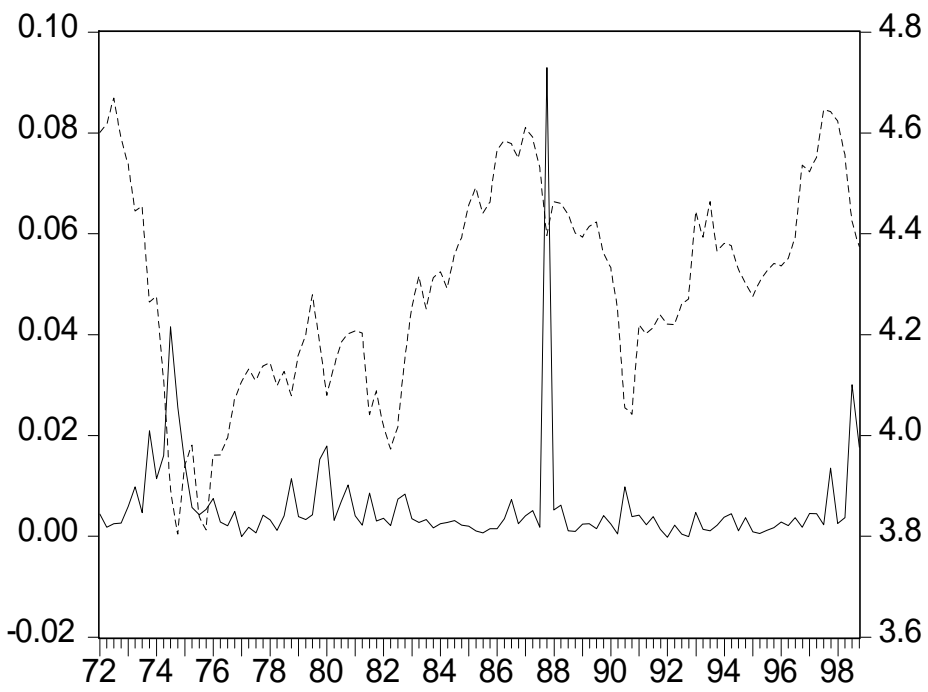

SYSTEMATIC_RISK ---- ASSET_PRICE

\section{Panel F}

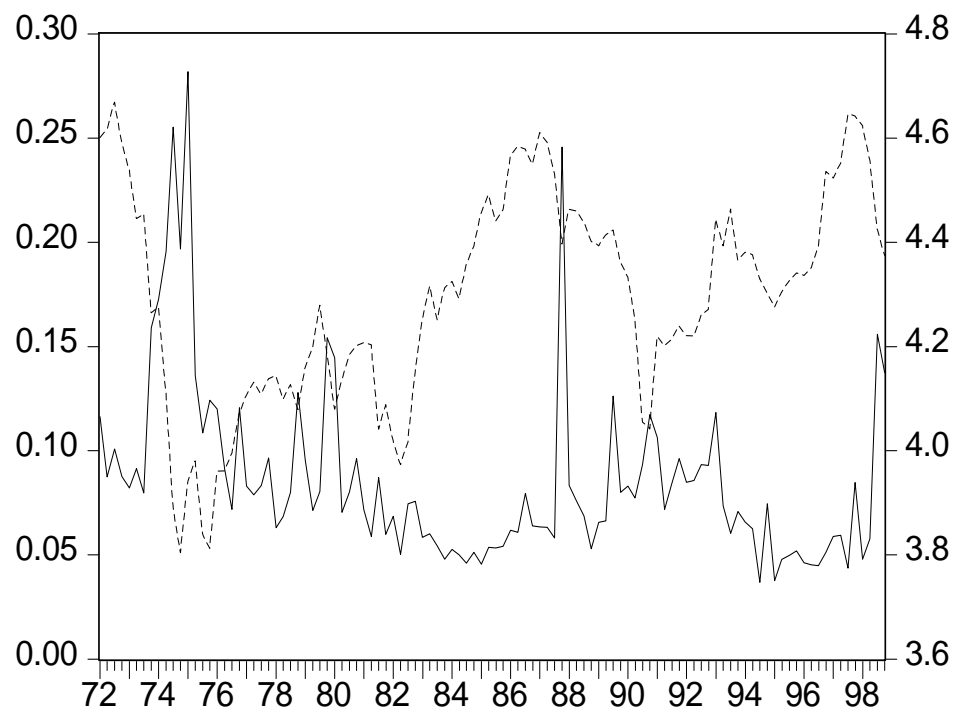


On Demand: Cross-Country Evidence from Commercial Real Estate Asset Markets 11

Figure 3 Time-Series Graphs of (Transformed) Demand Determinants Relative as Compared to Real Asset Price: Japanese Data

\section{Panel A}

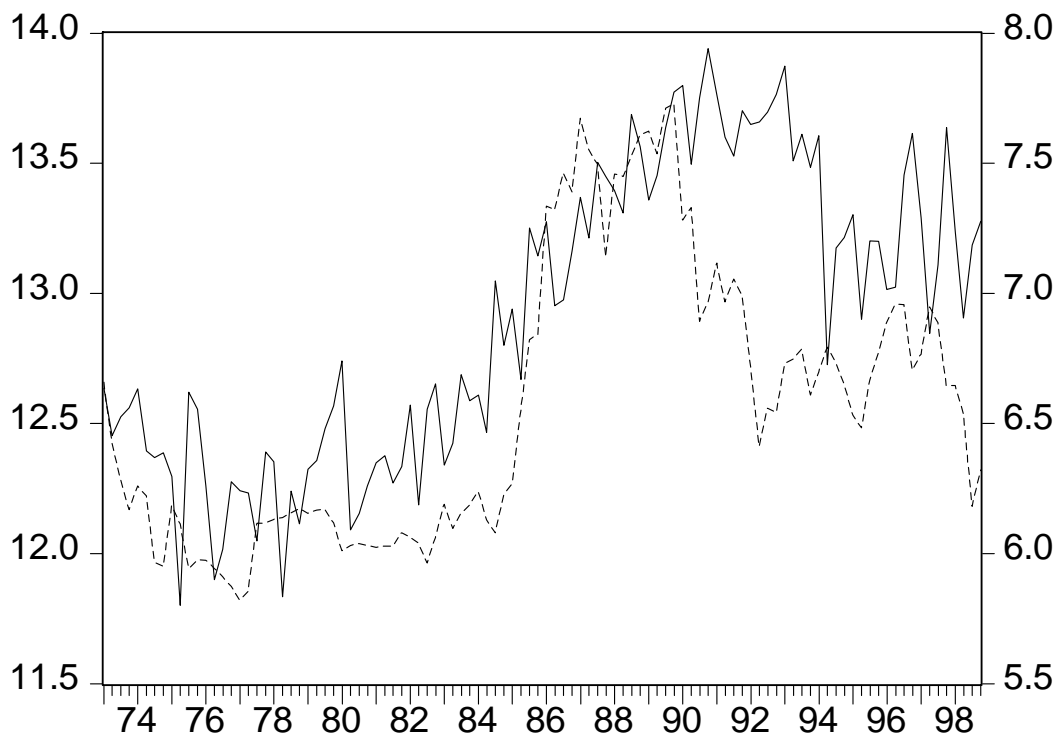

\section{— NEW_CONSTRUCTION ---- ASSET_PRICE}

Panel B

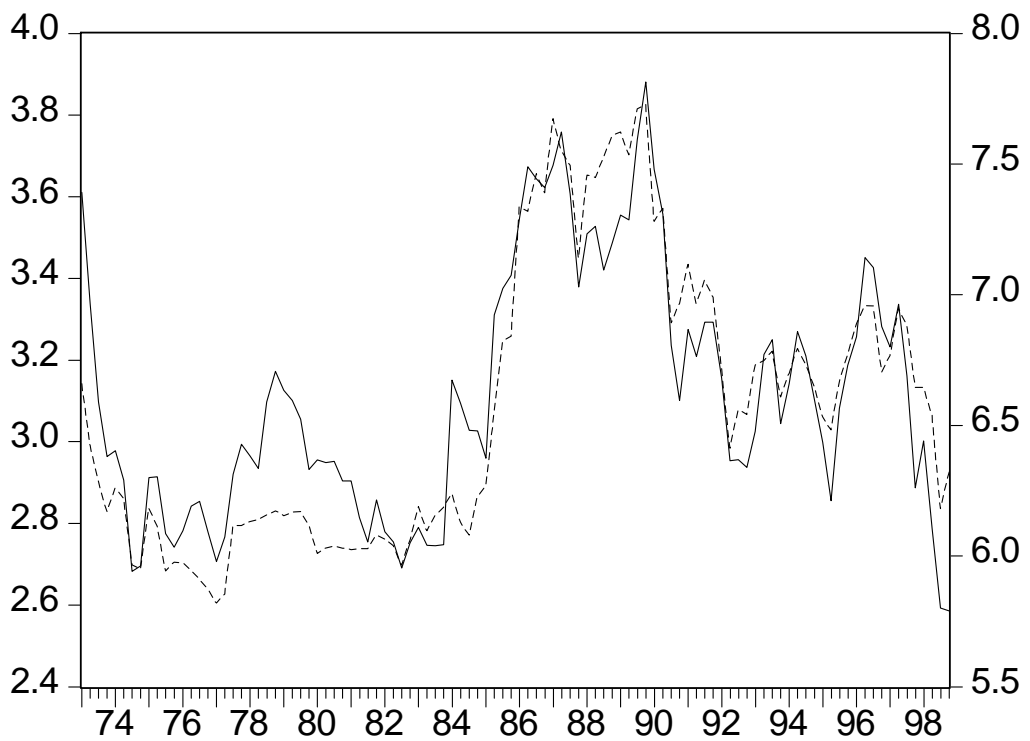


Panel C

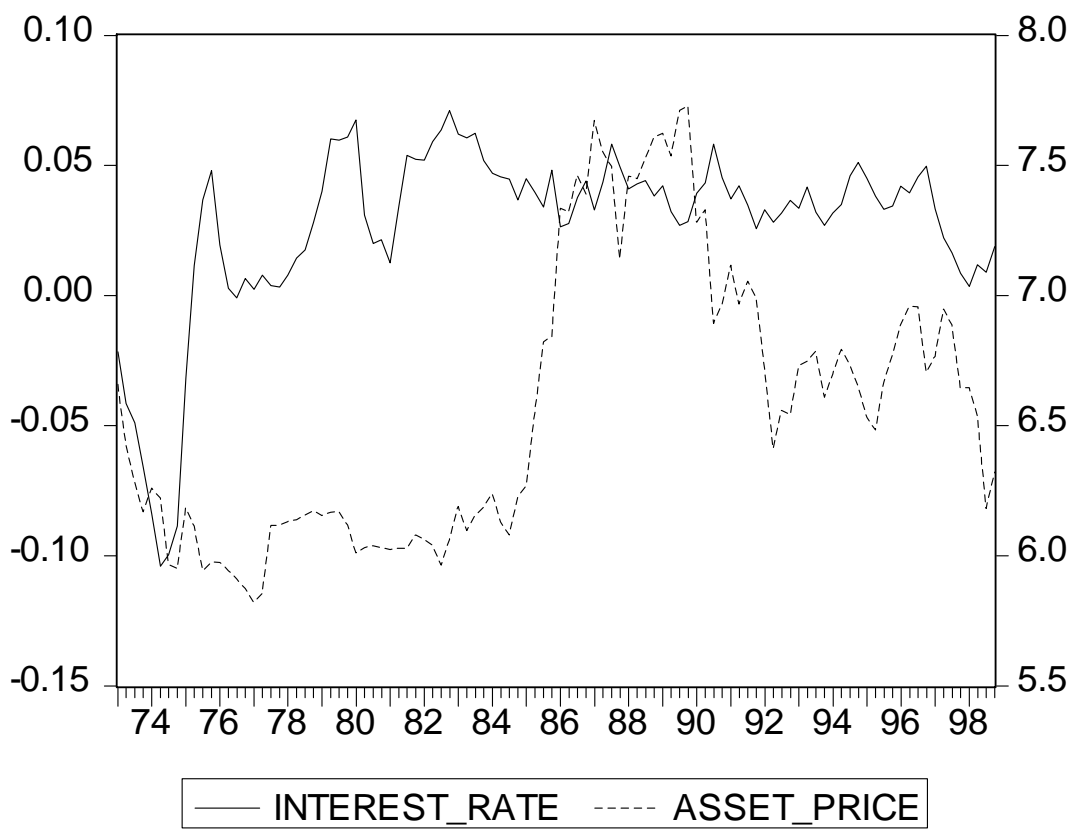

Panel D

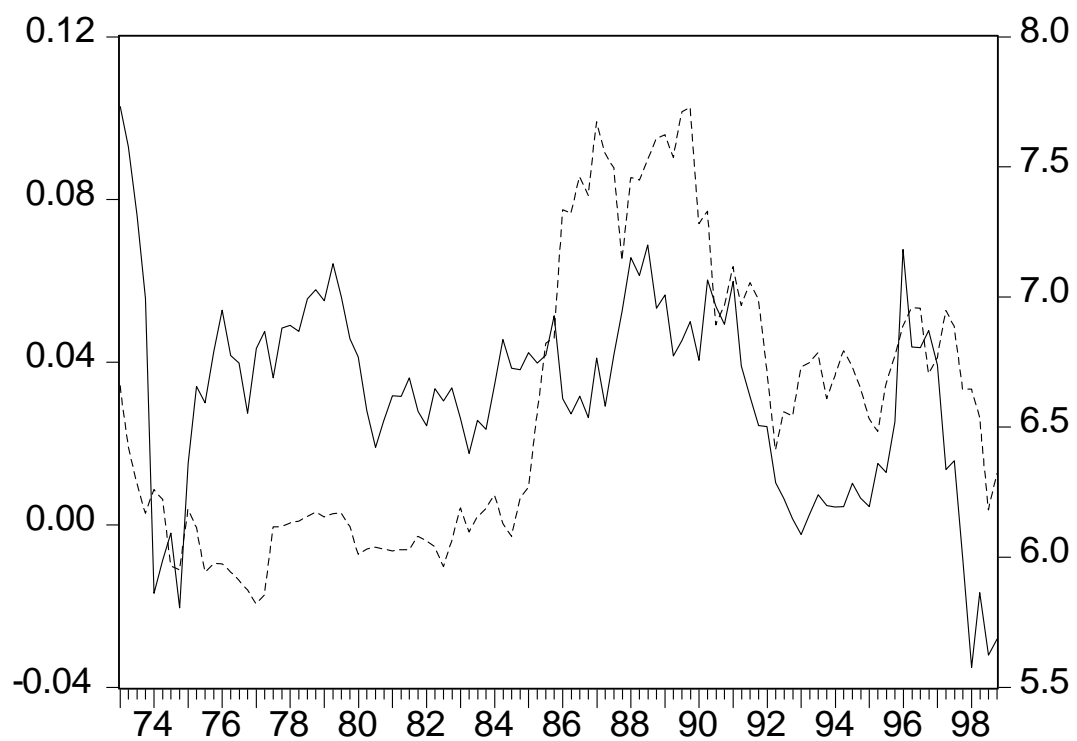

RENT_GROWTH -.-- ASSET_PRICE 
On Demand: Cross-Country Evidence from Commercial Real Estate Asset Markets 13

Panel E

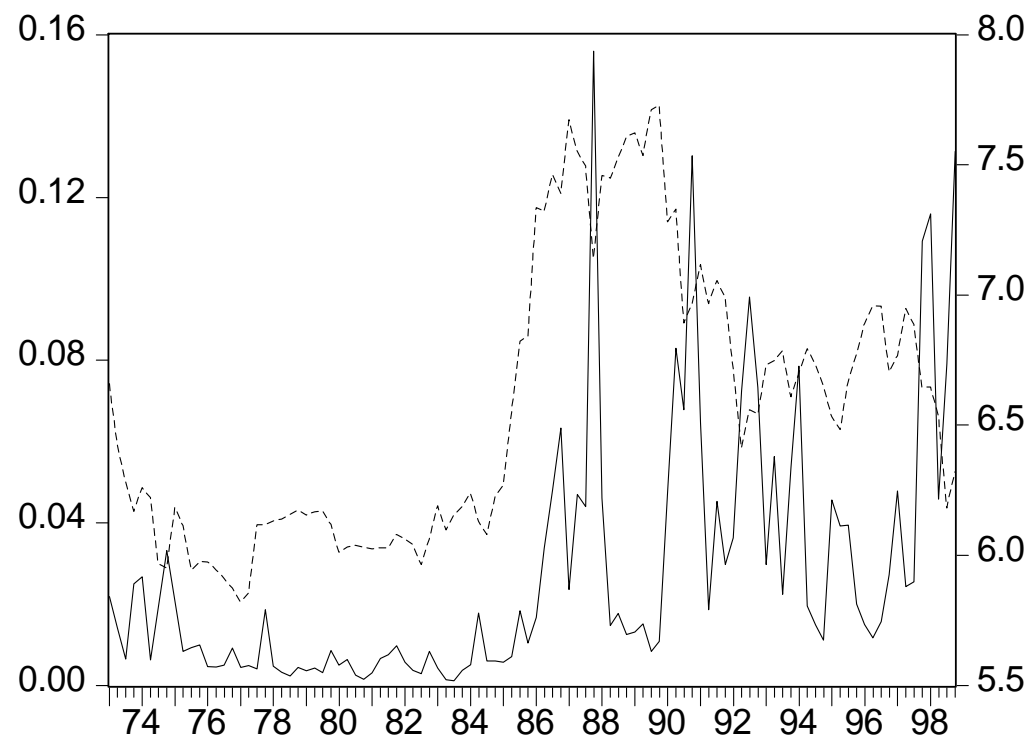

SYSTEMATIC_RISK ---- ASSET_PRICE

\section{Panel F}

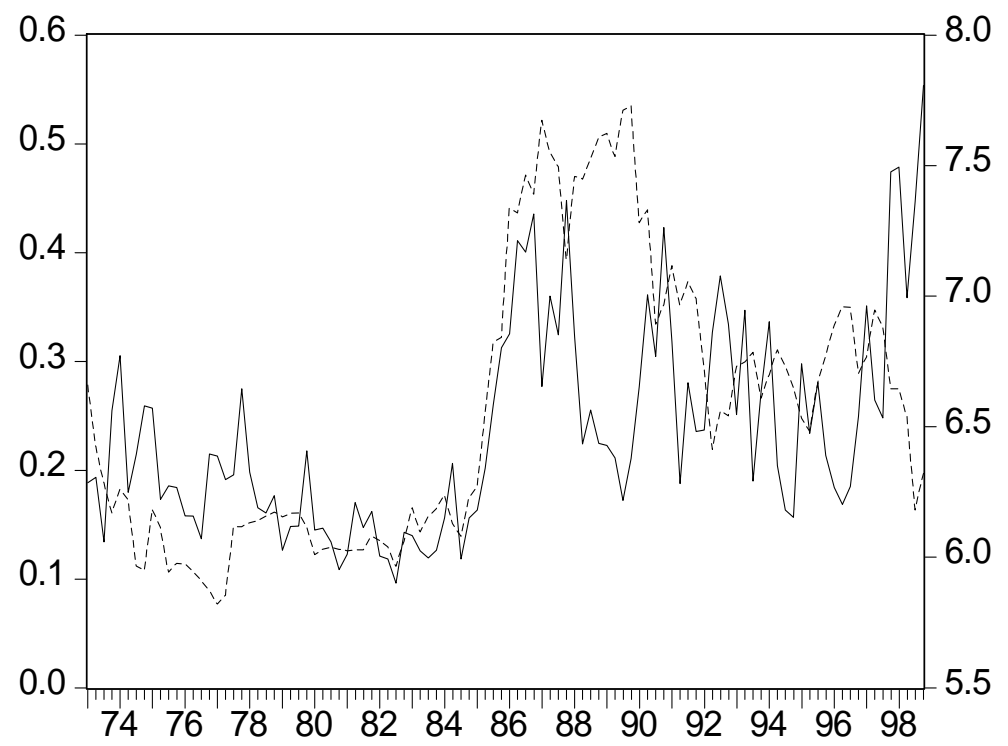




\section{Asset Price (P)}

U.S.: We use the log of an inflation-adjusted price index on publicly traded equity real estate investment trusts (REITs). An equity REIT is a collection of built commercial real estate assets; consequently, a broad-based index of equity REIT prices should reasonably approximate aggregate levels of commercial real estate asset prices. $^{2}$ Price indices are based on traded asset prices to reflect the fact that we are interested in returns to the built asset as opposed to a total return measure. To calculate the real price, we take the quarterly value-weighted NAREIT Equity REIT index and divide it by the quarterly CPI/100.

Japan: Price is measured by the log of an inflation-adjusted stock price index of commercial real estate companies listed on the Tokyo Stock Exchange. In Japan most commercial real estate is corporate-owned by separately capitalized and publicly traded real estate firms. The assets of these companies are generally not traded individually in the market, and are essentially held in perpetuity. Thus, a stock price index of this type should track aggregate commercial real estate values relatively closely.

Evolution of Asset Prices: Figure 1 displays the time series path of the log of real asset price for both the U.S. and Japan. Both series display significant variability with no real price appreciation over the respective sample periods. ${ }^{3}$ Note that prices declined significantly in 1974-75 in both series, which is a time period associated with the oil price shocks and significant unanticipated inflation. Prices then generally stabilized and increased (rather dramatically in the case of Japan) through 1987. Asset prices subsequently fell in the U.S. due to significant oversupply of space and the onset of the Savings \& Loan financial crisis. Prices bottomed out by the end of 1990 and began increasing thereafter, reflecting expectations as to improved fundamentals and a gradual return of liquidity to the market. In contrast, prices remained high in Japan until 1989, after which they fall significantly. The subsequent period is often referred to as the "post-bubble" economy in Japan, which debunked the "land myth" of ever-increasing nominal real estate prices.

\section{New Construction (C)}

U.S.: Real investment is measured by the log of the square feet of construction starts, as reported by F.W. Dodge. Construction starts are reported as the total square

\footnotetext{
${ }^{2}$ See Strange and Tang (2000) for evidence on the cointegration of public and private indices of commercial real estate prices.

${ }^{3}$ Using disaggregate, neighborhood-level data over a 400 year time frame, Eichholtz (1997) also finds no real increases in built asset prices. As a long-run phenomenon this outcome is somewhat surprising in the context of urban economic theory, which suggests that growth pressures in centralized, supply constrained markets will result in real property price increases. The lack of real price growth may be the result of technological improvements in transportation, the decentralization of cities, or other relevant factors.
} 
footage associated with announced projects, rather than the square footage actually completed or anticipated to be completed within a given quarter. ${ }^{4}$

Japan: New investment is measured by log of construction spending as reported by the Economic Planning Agency of Japan. Nominal construction spending is adjusted by a construction cost deflator to convert it into a real variable. This investment series measures construction in progress as well as construction that may have completed in a given quarter. It therefore provides a finer measure of starts and completions than the U.S. data, which are simply the aggregation of all announced construction starts. ${ }^{5}$

Anticipated Price Effect: No anticipated effect. As discussed earlier, financial asset pricing theory suggests that asset demand is insensitive to independent supply effects. Thus our null hypothesis is that supply exerts no direct effect on asset price. Reference to panel A in Figures 2 and 3 suggests that construction and price tend to move together over time. This is not surprising given the strong anticipated effect of asset price on new construction. What is surprising is that construction seems to be contemporaneous with, or actually lead, price at various points in the time series. For example, in the U.S. data prior to 1982, price and construction show a relatively strong contemporaneous relation, whereas construction seems to lead price during the investment/development boom of 1982-86. Then, in the post-1986 sample period, price appears to lead development. Similar lead/lag relations are apparent in the Japanese data as well. Construction leads suggest that supply information might be available to investors prior to the formal release date and, more importantly, that this information may be useful to investors in their determination of asset price.

\section{Construction Cost (K)}

U.S.: We use the log of the real cost per square foot of commercial real estate construction as reported by F.W. Dodge. Real costs are determined by taking the nominal construction cost and dividing it by the quarterly CPI/100. The construction cost data are obtained from F.W. Dodge.

Japan: The log of real construction cost is obtained by taking periodic nominal nondwelling construction cost and deflating it by a GDP deflator. Data are obtained from the Japanese Ministry of Construction.

\footnotetext{
${ }^{4}$ Completion data are available, but are based on a rigid formula that eliminates a fixed proportion of construction starts. This results in perfect cross-correlation between completions and starts (with a lag). More recently, F.W. Dodge has begun distinguishing between numerous stages of construction. These stages are pre-planning, planning, final planning, bidding, start, deferred and abandoned. Unfortunately, this classification scheme is recent and does not span our time series.

${ }^{5}$ Construction data are reported by several independent data sources in Japan, the series of which are all highly correlated with one another. We chose the data source with the longest quarterly time series.
} 
Anticipated Price Effect: No direct effect. This variable is used as an instrument in the supply equation in which asset market supply and demand are determined jointly (see equation (2)). Consequently, any construction cost effect is embedded in the supply variable.

\section{Net Rent (R)}

U.S.: To calculate the log of net real income, we first calculate a quarterly dividend yield using nominal NAREIT data, and multiply this yield by the nominal NAREIT Equity REIT index level. This provides a quarterly measure of net income. REITs are required by law to pay out at least 95 percent of their net income; thus, dividend yield is an accurate measure of income or net rents. We then take the nominal net income and divide it by the quarterly CPI/100 to convert it to a real rent measure, which is finally transformed by taking logs.

Japan: Periodic real rents are determined by multiplying real asset price by the income yield of the MTB-IKOMA real estate investment index. Income yields are only available annually, so we linearly trend intra-year rents using beginning and ending year income numbers. This nominal series is adjusted for inflation and is then transformed by taking logs.

Anticipated Price Effect: Positive. Increased rents imply an upward shift in the demand curve. Rational expectations suggest that asset price should lead rent on average. Reference to panel B of Figure 3 suggests that rent and asset price are closely related in Japan and that price tends to lead rent slightly. The anticipated relation is less clear-cut in the U.S. data (see panel B of Figure 2). For example, the U.S. data show that rents and prices move synchronously over the periods 1973-76 and 1984-91, with prices appearing to lead rents by one to four quarters on average. However, in other periods this general relation fails to hold, suggesting a complex or non-constant relationship between the two variables.

\section{Risk-Free Interest Rate (r)}

U.S.: We use the 10-year Treasury bond rate minus expected inflation. Expected inflation is calculated by dividing next quarter's CPI by this quarter's CPI and then subtracting one. The interest rate data source is Federal Reserve Board statistics.

Japan: 10-year yields on Japanese Government bonds as listed on the Tokyo stock exchange are used. Expected inflation is subtracted to create a measure of real interest rate. Expected inflation is calculated as next quarter's GDP deflator divided by this quarter's GDP deflator and then subtracting one. The data source is DataStream.

Anticipated Price Effect: Negative. We use 10-year government bond yields rather than short-term bond yields due to the relative illiquidity of commercial real estate, its durability, and because the quality and availability of short-term government bond yield data in Japan is questionable. See Cornell (1999) for justification of the use of longer-term interest rates to discount cash flows from illiquid, long duration capital investments. Visual inspection of Panel $\mathrm{C}$ of Figures 2 and 3 suggests that 
asset prices and interest rates only periodically display the anticipated negative relationship. The negative relation appears to be more clear-cut in the U.S. data than in the Japanese data. ${ }^{6}$

\section{Rental Growth Rate (g)}

U.S.: The expected growth rate in income is proxied by the growth rate of real GDP. Because the demand for space is derived from aggregate economic activity, and because there is often a lag between macroeconomic growth and space market demand, a broad indicator of growth is employed.

Japan: The growth rate of real GDP is used here as well, for the similar reasons and with similar restrictions.

Anticipated Price Effect: Positive. Higher cash flow growth implies a lower income capitalization rate, which in turn implies an upward shift in asset demand. See Quan and Titman (1999) for evidence on the strength of the commercial real estate return and GDP growth rate relation. Reference to panel D of Figures 2 and 3 suggests a somewhat murky, but generally positive relation between asset price and GDP growth rate. The link between asset price and GDP growth appears to be more clearcut in the Japanese series than the U.S. series.

\section{Systematic Risk $\left(\sigma_{P, M}\right)$}

U.S.: Systematic risk is proxied by the covariance of equity REIT returns and an index of market returns. We use CRSP data tapes to first calculate the valueweighted average daily return for a cross-section of equity REITs for each day in the quarter. To obtain a covariance measure, these returns are then matched with a time series of daily returns over the quarter of a value-weighted CRSP-based market index. The average return of daily equity REIT returns and market index returns are also computed over the entire quarter in the calculation of the covariance measure. The covariance measure is annualized for model estimation.

Japan: We apply a similar procedure to obtain a measure of systematic risk associated with Japanese commercial real estate. We take a value-weighted average daily return for a cross-section of Japanese commercial real estate companies. The TOPIX index is used to obtain daily returns to the market portfolio, as reported by the Tokyo Stock Exchange. As with US data, the covariance measure is annualized for model estimation

\footnotetext{
${ }^{6}$ In particular, note the large negative real rates of interest realized in Japan from 1973-75. Closer examination of government bond yield data during this period shows that 10 -year nominal government bond yields remained at relatively modest levels (eight to nine percent). During this period, these yields disengaged from nominal 3-month CD and the 5year interest bearing bank debenture yields, which increased substantially in response to increased inflation (these three yield measures track closely to one another throughout the remainder of our sample period, both in levels and in first differences). We choose not to use these alternative interest rate measures, however, for reasons expressed above and because they are posted rates as opposed to yields resulting from traded security values.
} 
Anticipated Price Effect: Negative. An increase in systematic risk increases the rate at which cash flows are discounted to shift the demand curve downward. ${ }^{7}$ Reference to panel E of Figures 2 and 3 suggests the anticipated relation is often realized in the data. Note the large spike in covariance in the latter part of 1987 in both the US and Japanese series. This coincided with the stock market crash in October of that year, and clearly demonstrates that, although risk sharing benefits can be realized in "normal" or "good news" markets, these benefits often vaporize when strong negative financial shocks occur. ${ }^{8,9}$ Note the similar but less dramatic covariance spikes that occurred in 1974 due to the oil price shock of that year and a significant stock market decline, and in 1998 due to the Russian financial crisis. There is also a significant spike in 1990 in the Japanese data that coincided with the beginning of the end of the bubble economy. Finally, note that covariance levels in Japan plateau to higher average values after 1985. This coincides (with a slight lag) with the opening of Japanese securities markets to foreign investment as well as a large increase in public security issuances and exchange trading activity. For example, the ratio of foreign bond investment to total assets increased three-fold over the 1983-89 time period, and has remained at the new percentage level after 1989.

\section{Total uncertainty $(\sigma)$}

U.S.: Total uncertainty is proxied by the standard deviation of daily equity REIT rates of return over the quarter. The method for calculating daily and average daily REIT returns is identical to that used to calculate the covariance measure. This within-quarter, pooled cross-sectional time-series approach to determining unanticipated variation in asset price (as well as covariance in asset price with the market) is preferred to a pure time-series approach for several reasons. First, there is less reliance on historical data (of quarterly observations) in a setting in which investment opportunities change over time. Second, and perhaps most importantly, our approach is less susceptible to measurement error when structural relations exist in real asset markets. That is, the historical volatility of asset price may have a significant predictive component that is due to structural interactions between asset and space markets. If this is the case, then a simple time-series measure of asset price volatility will overstate total uncertainty (Lai and Wang 1998). Moreover, bias associated with the time series measure will also vary over time. Lastly, note that the standard deviation of returns are annualized for model estimation.

Japan: Total uncertainty is measured by the standard deviation of daily real estate index returns over the quarter. The method for calculating daily real estate security

${ }^{7}$ Because price is specified to depend on current and lagged observables in our model, systematic risk is an input to the model - it is not estimated. When systematic risk is estimated (often cross-sectionally) in a financial asset pricing context, the relation between expected price (return) and systematic risk is typically positive.

${ }^{8}$ See Kindleberger (1996), Morris (1999) and Stulz (1999) for more detailed discussions of this issue.

${ }^{9}$ This observation is obviously a considerable outlier and thus creates the potential to bias model estimation. The effect of this event turns out to be benign, and is addressed in the following section when we report our estimation results. 
returns is identical to that used to calculate the covariance of returns in the determination of systematic risk. The standard deviation of returns are annualized for model estimation.

Anticipated Price Effect: No anticipated effect. After controlling for systematic risk, total uncertainty is a measure of idiosyncratic risk in asset investment. Classical financial asset pricing theory generally posits no role for idiosyncratic risk, since diversification is assumed to be achievable at a trivially low cost. However, as noted earlier, there is reason to believe that idiosyncratic risk may be relevant to investors in commercial property markets. Uncertainty-price relations differ markedly between countries, as seen in panel F of Figures 2 and 3. A murky, possibly negative relation appears to exist in the U.S. series, whereas a generally positive relation is apparent in the Japanese series. These relations must be interpreted cautiously, however, since the systematic component of risk is embedded in the total uncertainty measure. Observe that total uncertainty is higher in absolute terms in Japan as compared to the U.S. Comparison of balance sheet characteristics suggest that differences may be due to the more liberal use of leverage by Japanese property companies. Finally, note the volatility spikes coinciding with the 1974 oil shock, the 1987 financial market crash, the 1990 Japanese bubble deflation and the 1998 Russian financial crisis, as well as the plateauing of total uncertainty in the post1985 era in Japan.

\subsection{Relation to Empirical Tests of Financial Asset Pricing Models}

There are numerous differences between our real asset demand model specification and standard multi-factor financial asset pricing model specifications. Our focus is on the demand for investment in durable, income producing real assets, in which there may be a structural relation between the asset price and new investment. In real asset market equilibrium, built asset price is relevant to developers who make investment decisions. New investment may then channel through to exert an independent effect on asset price. This focus requires using observed (ex-dividend) asset prices to estimate inverse demand. In contrast, financial asset pricing models focus on total returns in estimation in which demand is thought to be infinitely price elastic. This difference in the return to capital versus total financial return is likely to have little practical effect in the estimation, however, since income and dividend yields to commercial real estate investment tend to be relatively stable over time.

With respect to the determinants of asset price, in our specification there is no attempt to identify orthogonal pricing factors as required by Ross's arbitrage pricing model (1976). The choice of our price variables is driven by the structural characteristics of commercial real estate markets in which relevant space, financial, and macroeconomic market conditions determine asset demand.

Net rent levels are determined in space market equilibrium at any given point in time, which then serve as a cash flow determinant of asset demand. Cash flow growth rates are determined by macroeconomic conditions as they impact commercial space markets. Interest rate and systematic risk are familiar financial 
market variables used to determine the rate at which cash flow is discounted in equilibrium. It is important to note that systematic risk is an input to our model of real asset demand, whereas it is estimated (i.e., it is a "factor loading") in standard financial asset pricing models. That is, we posit that systematic risk is priced rather than testing to see if it is priced. This approach is consistent with our focus on how the structure of current market conditions affect real asset demand, as opposed to focusing on expected prices over the next period.

A secondary reason for using covariance as an input is that CAPM-style model specifications have typically performed poorly with commercial real estate data (i.e., $\beta$ is typically small and often statistically insignificant). When the investment opportunity set is subject to a continuous series of unanticipated shocks, it may be that investors are more concerned with the second moment of asset price return than the first moment (see Merton 1990, p.509) for further elaboration on this point).

Another important difference is that we allow for the possibility that lagged explanatory variables may impact investor asset demand. This is in contrast to standard financial asset pricing models that typically consider contemporaneous effects only. Although (transaction costless) theory often suggests that contemporaneous values of demand determinants are sufficient to determine asset price, in reality there are often important trends and path dependencies in the data that are potentially informative to investors. For example, unanticipated shocks to the investment opportunity set may result in complex state variable processes that necessitate the use of historical time series of state variables (Merton 1973). ${ }^{10}$ Inspection of the graphs in panels $\mathrm{E}$ and $\mathrm{F}$ in Figures 2 and 3 indeed suggest that equilibrium discount rates and total asset volatility change continuously over time, in contrast to standard log-normal time-series specifications that assume these variables are constant. Market imperfections, which may be quite important in decentralized real asset markets, may also result in lags in information distribution that create path dependencies. Noisy rational expectations suggest that investors will analyze sequences of price determinants to make inferences about true prices. ${ }^{11}$ Use of historical data (as well as "volume" related measures such as real investment) can allow investors to disentangle pure information effects from more transitory effects such as liquidity in the process of asset price discovery.

\section{Estimation Results}

\subsection{Preliminaries}

10 There have been a number of more recent empirical papers that examine lead-lag relations in financial asset pricing context. See, for example, Engle and Grainger (1987).

11 Microstructure models often require analysis of past sequences of prices to make inferences as to the current price. In our case, knowing something about the structure of asset market equilibrium allows us to analyze past sequences of price determinants (as well as prices themselves) to infer the true current price. 
Given that our data are time series, the first step in our preliminary analysis of the data is to examine each series for nonstationarity. Using the augmented DickeyFuller test (see Dickey and Fuller, 1979, 1981), nonstationarity cannot be rejected in the cases of both U.S. and Japanese data for the log of real asset price $(P)$, the log of construction starts $(C)$, the log of the real cost of construction $(K)$, the log of real net rent level $(R)$, and total uncertainty $(\sigma)$. Nonstationarity also cannot be rejected for the real rate of interest $(r)$ in the U.S. data as well as the rental growth rate $(g)$ and systematic risk $\left(\sigma_{P, M}\right)$ in the Japanese data. Hence, we assume these series are nonstationary. Conversely, the U.S. measures of the growth rate of real GDP $(g)$ and systematic risk $\left(\sigma_{P, M}\right)$, as well as Japan's real rate of interest $(r)$, appear to be stationary. Unit root tests of all of the series in their first differences reject nonstationarity.

Using Engle and Granger's (1987) method, we conduct pair-wise cointegration tests of the price variable with explanatory variables that appear in the demand equation (see equations (1) and (2a)). This is done at all relevant current and lagged (as well as possibly lead) values for the non-stationary series (justification for lead/lag variable inclusion will be discussed momentarily). We find no evidence of cointegration of the asset price variable with any of the other nonstationary series. ${ }^{12}$ Therefore, the error term in any regression with the log of asset price as the dependent variable is likely to be nonstationary, implying biased and inconsistent parameter estimates. To make the error term stationary, it is necessary to use first differences of all of the nonstationary series. Furthermore, in order not to change the economic meaning of the equations, it is also necessary to use first differences of the series that are already stationary. ${ }^{13}$

For reasons discussed earlier, lags of the exogenous variables may be relevant to investors in the determination of asset price. In a distributed lag model the price and error term must be uncorrelated at all leads and lags to get unbiased coefficient estimates - i.e., it is not sufficient that the current price is uncorrelated with the current error term. As a result we write $\Delta P$, the change in asset price, as a function of the current and eight quarters of lagged values of the first differences of all nonconstruction variables except the rent variable, $\Delta R$. In the case of rents, we include the one quarter forward realized change in rent as well as the current and seven lagged values. We do this because, in theory, price depends on next period's capitalized income. We limit the lags to eight quarters (two years) for parsimony and

12 We actually did find evidence that price is cointegrated with certain lagged values of the rent and uncertainty variables in the U.S. data. However, because cointegration was not apparent at all of the current and lagged values, and to facilitate comparison between the U.S. and Japanese estimation results, we prefer to take a more conservative approach and reject cointegration of price with exogenous variables.

13 The consequences of over-differencing (i.e., assuming a series is nonstationary when it is really stationary) are known to be much less severe than the consequences of underdifferencing (i.e., assuming a series is stationary when it is really nonstationary). See Stock and Watson (1988) for a discussion of the consequences of estimating regressions with nonstationary variables. 
because a preliminary analysis of the data shows that longer lags generally do not affect current price.

\subsection{Endogenous Supply}

The issue of which leads or lags to include for the construction variable in model 2 (see equation (2)), and how to interpret these variables, requires additional discussion. This is due to the information content of announced construction starts and its possible endogeneity or exogeneity with asset price at all of the leads and lags. One approach is to assume that construction starts as reported by F.W. Dodge (in the U.S. data) and the Economic Planning Agency (in the Japanese data) provide new information to the marketplace regarding supply. This suggests a structural model specification that allows time $t$ construction to endogenously determine time $t$ asset price. We also include up to eight lagged construction periods in the estimation of asset price. Previously announced construction starts in combination with current starts may inform investors as to unexpected changes in previously announced projects, as well provide additional information as to the microstructure of asset prices. Lagged construction variables are treated as exogenous in the estimation. ${ }^{14}$

Real estate development is a process that typically begins well before the announcement of a construction start. This suggests that currently reported construction starts may provide stale information regarding additions to the stock of space. In a second variation of the endogenous supply model specification, we assume that endogenous construction starts lead asset price by an appropriate number of periods. We choose an eight period lead in reported construction starts as our endogenous supply number, under the assumption that commercial development projects often require two years of planning and review before construction actually begins (see Wheaton 1999). Up to 16 quarters (four years) of subsequent construction start data are included in this model specification to reflect the pre- and post-construction start time periods. These "lagged" construction start numbers are treated as exogenous variables in the estimation.

The inclusion of supply-leads in the demand equation requires modification of the first-stage supply equation. In order to ensure that endogenous supply does not contain any non-construction variable effects that would imply a lead in asset price, all non-construction explanatory variables that appear in the demand equation are restricted to lag construction by at least eight quarters. Leads in construction starts and real construction cost are allowed, as the latter variable cost is an instrument in the supply equation.

In summary, to account for differencing and lead/lag effects in the explanatory variables, we reexpress the original specifications seen in equations (1) and (2) to reflect modifications required to the model:

14 Endogenizing the effects of lagged construction variables would require alternative construction data series that track individual construction projects through completion. Unfortunately, way are not aware of any such series (see footnote 4). 
On Demand: Cross-Country Evidence from Commercial Real Estate Asset Markets 23

\section{Model 1}

$$
\begin{aligned}
\Delta P(t)= & \alpha_{0}+\alpha_{1} \Delta R(t+1, t, \ldots, t-7)+\alpha_{2} \Delta r(t, \ldots, t-8)+\alpha_{3} \Delta g(t, \ldots, t-8)+ \\
& \alpha_{4} \Delta \sigma P, M(t, \ldots, t-8)+\alpha_{5} \Delta \sigma(t, \ldots, t-8)+\alpha_{6} \Delta \varepsilon P(t-1)+\Delta \varepsilon P(t)
\end{aligned}
$$

\section{Model 2 (Endogenous Current Supply)}

$$
\begin{aligned}
\Delta P(t)= & \alpha_{0}+\alpha_{1} \Delta R(t+1, t, \ldots, t-7)+\alpha_{2} \Delta r(t, \ldots, t-8)+\alpha_{3} \Delta g(t, \ldots, t-8)+\alpha_{4} \Delta \sigma_{P, M}(t, \ldots, t-8) \\
& +\alpha_{5} \Delta \sigma(t, \ldots, t-8)+\alpha_{6} \Delta C(t, \ldots, t-8)+\alpha_{7} \Delta \varepsilon_{P}(t-1)+\Delta \varepsilon P(t) \\
\Delta C(t)= & \beta_{0}+\beta_{1} \Delta P(t, \ldots, t-8)+\beta_{2} \Delta K(t, \ldots, t-8)+\beta_{3} \Delta r(t, \ldots, t-8)+\beta_{4} \Delta g(t-1, \ldots, t-8)+ \\
& \beta_{5} \Delta \sigma_{P, M}(t, \ldots, t-8)+\beta_{6} \Delta \sigma(t, \ldots, t-8)+\beta_{7} \delta 1+\beta_{8} \delta 2+\beta_{9} \delta 3+\Delta \varepsilon C(t)
\end{aligned}
$$

\section{Model 3 (Endogenous 8-Quarter Lead in Supply)}

$$
\begin{aligned}
\Delta P(t)= & \alpha_{0}+\alpha_{1} \Delta R(t+1, t, \ldots, t-7)+\alpha_{2} \Delta r(t, \ldots, t-8)+\alpha_{3} \Delta g(t, \ldots, t-8)+\alpha_{4} \Delta \sigma_{P, M}(t, \ldots, t-8) \\
& +\alpha_{5} \Delta \sigma(t, \ldots, t-8)+\alpha_{6} \Delta C(t+8, \ldots, t-8)+\alpha_{7} \Delta \varepsilon_{P}(t-1)+\Delta \varepsilon P(t) \\
\Delta C(t+8)= & \beta_{0}+\beta_{1} \Delta P(t, \ldots, t-8)+\beta_{2} \Delta K(t+8, \ldots, t)+\beta_{3} \Delta r(t, \ldots, t-8)+\beta_{4} \Delta g(t-1, \ldots, t-8) \\
& +\beta_{5} \Delta \sigma_{P, M}(t, \ldots, t-8)+\beta_{6} \Delta \sigma(t, \ldots, t-8)+\beta_{7} \delta 1+\beta_{8} \delta 2+\beta_{9} \delta 3+\Delta \varepsilon C(t)
\end{aligned}
$$

where the coefficients $\alpha_{1}, \ldots, \alpha_{6}$ and $\beta_{1}, \ldots, \beta_{6}$ are vectors over the appropriate current, lagged and possibly leading explanatory variables, and $\delta 1, \delta 2$ and $\delta 3$ are seasonal dummies for quarters 1,2 and 3 , respectively. ${ }^{15,16}$

Thus we will consider three asset demand model specifications: Model 1, Model 2 with endogenous current (time $t$ ) construction, and Model 2 with an endogenous 8quarter lead (time $t+8$ ) in construction. The second and third models will be estimated using 2SLS. The third model may very well be the most general specification. It allows for potential supply effects and reasonably approximates how information is likely to flow through to market participants in the determination of asset market equilibrium.

15 Note that we make a slight adjustment in the construction equation as expressed in (4b) and (5b). We include lags but do not include the current value of $g$ because of potential endogeneity: an increase in commercial real estate construction causes an increase in real GDP growth by definition.

16 Seasonality effects were detected when undertaking unit root tests of the construction variable. As a result the first-stage supply equation as seen in Model 2 also includes seasonal dummies. 


\subsection{Findings}

Demand equation estimates using U.S. and Japanese data are reported in Tables 1 and 2 , respectively. The number of lags and leads to include in each equation is determined by maximizing adjusted- $\mathrm{R}^{2}$. With this method it may happen that certain variables are excluded in the final regression equation. If more than one lagged or current (or possibly lead) variable is included in the final demand equation estimation, then only the sum of the variable coefficients and the standard error of the sum are reported. It can also sometimes happen that a variable is included in the regression for which the sum is statistically insignificant. This is typically the result of individual lags that have sizable coefficients - and hence are required to be included in the model - but are of opposite sign and thus partially cancel out over the sum.

\subsubsection{Estimation Results: U.S.}

The plan for this section is to analyze the U.S. results first, followed by a comparative analysis of the Japanese and U.S. results. Consider the model parameter estimates displayed in Table 1. As seen in column (1) - which is the model that excludes supply effects on a priori grounds - coefficient signs are as expected for the Net Rent $(R)$, Interest Rate $(r)$, and Income Growth Rate $(g)$ variables. The interest rate and income growth rate variable coefficients are statistically significant at the one percent level. The economic interpretation of the coefficients is that a one percentage point change in the sum of Net Rent (Interest Rate, Income Growth Rate) results in a $.275(-6.15,2.24)$ percentage point change in current Asset Price. ${ }^{17}$ Conventional pricing theory suggests that the net rent coefficient equals one. The rather small income coefficient estimate may follow from the use of short to medium lease terms and the lack of a forward market in lease contract rates, which result in a relatively uninformative price signal to investors.

Contrary to expectations, the Systematic Risk variable coefficient is positive and statistically insignificant and the Total Uncertainty variable coefficient is negative and statistically significant. These estimates lend some initial empirical support to the notion that idiosyncratic risk may be priced by investors and that it may be more important than systematic risk in the determination of real asset price. The economic interpretation of these coefficient estimates is that a one percentage point increase in the respective sums of Systematic Risk and Total Uncertainty result in .375 and -2.34 percent increases in current Asset Price. ${ }^{18}$

17 Interest rate and income growth rate are expressed as annualized percentages, whereas price changes are quarterly. To obtain annualized price changes as a result of a one percentage point increase in those variables, multiply by four.

18 These quantities are also annualized numbers: thus one should multiply by four to annualize the price effect. Also, recall that covariance is a squared quantity while standard deviation is not. Thus a one percentage point increase in covariance is much larger on a relative basis than a one percentage point increase in standard deviation. 
Table 1 Determinants of the Demand for Commercial Real Estate: Estimates Using U.S. Data (Dependent Variable: $\Delta \mathbf{P}(\mathbf{t}))$

\begin{tabular}{|c|c|c|c|}
\hline Determinants of Demand & $\begin{array}{c}\text { (1) } \\
\Delta \mathrm{C} \text { Excluded } \\
74: 2-98: 4 \\
\end{array}$ & $\begin{array}{c}(2) \\
\Delta \mathrm{C}(\mathrm{t}) \text { Endogenous } \\
74: 3-98: 3\end{array}$ & $\begin{array}{c}(3) \\
\Delta \mathrm{C}(\mathrm{t}+8) \text { Endogenous } \\
74: 3-96: 4\end{array}$ \\
\hline Constant & --- & --- & $\begin{array}{c}.0079 \\
(.0077)\end{array}$ \\
\hline $\begin{array}{l}\text { Sum of 1-Quarter Lead, } \\
\text { Current \&Lagged } \Delta R \\
\text { (Net Rent) }\end{array}$ & $\begin{array}{c}.275[6] \\
(.190)\end{array}$ & $\begin{array}{c}.417 \quad[7] \\
(.278)\end{array}$ & $\begin{array}{l}.513^{* *}[7] \\
(.258)\end{array}$ \\
\hline $\begin{array}{c}\text { Sum of Current \& Lagged } \\
\Delta r \text { (Interest Rate) }\end{array}$ & $\begin{array}{c}-6.146^{* * *}[3] \\
(1.568)\end{array}$ & $\begin{array}{l}-4.066^{* *}[3] \\
\quad(1.892)\end{array}$ & $\begin{array}{l}-1.946 \quad[6] \\
\quad(2.097)\end{array}$ \\
\hline $\begin{array}{c}\text { Sum of Current \& Lagged } \\
\Delta g \text { (Growth Rate) }\end{array}$ & $\begin{array}{l}2.239^{* * *}[5] \\
(.758)\end{array}$ & $\underset{(.822)}{1.684^{* *}}[7]$ & $-\frac{-.108}{(.224)}[3]$ \\
\hline $\begin{array}{c}\text { Sum of Current \& Lagged } \\
\Delta \sigma_{P, M} \text { (Systematic Risk) }\end{array}$ & $\begin{array}{l}.375 \quad[5] \\
(2.237)\end{array}$ & $\begin{array}{l}-5.353^{* * *}[3] \\
(1.484)\end{array}$ & $\begin{array}{l}-7.559^{* * *}[6] \\
(1.412)\end{array}$ \\
\hline $\begin{array}{l}\text { Sum of Current \& Lagged } \\
\Delta \sigma \text { (Total Uncertainty) }\end{array}$ & $\begin{array}{c}-2.336^{* * *}[5] \\
(.679)\end{array}$ & $\begin{array}{c}-.169[6] \\
(.894)\end{array}$ & $\begin{array}{l}1.672^{* * *}[4] \\
\quad(.459)\end{array}$ \\
\hline $\begin{array}{c}\text { Sum of Current, Lead \& } \\
\text { Lagged } \Delta C \text { (New Supply) }\end{array}$ & & $\begin{array}{c}.118[5] \\
(.110)\end{array}$ & $\begin{array}{c}.457^{* *}[14] \\
(.231)\end{array}$ \\
\hline$\rho$ & --- & $\begin{array}{l}.275^{* *} \\
(.128)\end{array}$ & $\begin{array}{l}.503^{* * *} \\
(.133)\end{array}$ \\
\hline $\begin{array}{c}\mathrm{R}^{2} \\
\text { Adjusted- } \mathrm{R}^{2} \\
\text { Durbin-Watson } \\
\end{array}$ & $\begin{array}{l}.539 \\
.397 \\
1.77 \\
\end{array}$ & $\begin{array}{l}.654 \\
.489 \\
2.04 \\
\end{array}$ & $\begin{array}{l}.871 \\
.761 \\
1.83 \\
\end{array}$ \\
\hline
\end{tabular}

The dependent variable is the change in log of price of commercial real estate. $\rho$ is the estimate of the coefficient of first-order auto-correlation in the error term. Coefficient standard errors are in parentheses. " indicates statistical significance at the 10 percent level, ${ }^{* *}$ indicates statistical significance at the 5 percent level and ${ }^{* * *}$ indicates statistical significance at the 1 percent level. The criteria used for determining current and lagged variables to include in the model is maximized adjusted- $\mathrm{R}^{2}$. The actual number of current and lagged (and possibly lead) variables included in model estimation is shown in brackets next to the coefficient estimate in each equation. Three different specifications are considered: one in which demand for commercial real estate is assumed to be completely elastic (column (1)), one in which demand is endogenously determined as a function of the reported current change in supply (column (2)), and one in which demand is endogenously determined as a function of the reported eight quarter lead in change in supply (column (3)). 
Table 2 Determinants of the Demand for Commercial Real Estate: Estimates Using Japanese Data (Dependent Variable: $\Delta P(t)$ )

\begin{tabular}{|c|c|c|c|}
\hline Determinants of Demand & $\begin{array}{c}(1) \\
\Delta C \text { Excluded } \\
75: 1-98: 3 \\
\end{array}$ & $\begin{array}{c}(2) \\
\Delta \mathrm{C}(\mathrm{t}) \text { Endogenous } \\
75: 2-98: 3 \\
\end{array}$ & $\begin{array}{c}(3) \\
\Delta \mathrm{C}(\mathrm{t}+8) \text { Endogenous } \\
75: 2-96: 4 \\
\end{array}$ \\
\hline Constant & $\begin{array}{l}.0058 \\
(.0053)\end{array}$ & $\begin{array}{l}.0055 \\
(.0054)\end{array}$ & --- \\
\hline $\begin{array}{c}\text { Sum of 1-Quarter Lead, } \\
\text { Current \&Lagged } \Delta R \\
\text { (Net Rent) }\end{array}$ & $\begin{array}{c}1.476^{* * *}[7] \\
(.164)\end{array}$ & $\begin{array}{l}1.325^{* * *} \\
(.169)\end{array}$ & $\begin{array}{l}1.175^{* * *} \quad[8] \\
(.185)\end{array}$ \\
\hline $\begin{array}{c}\text { Sum of Current \& Lagged } \\
\Delta r \text { (Interest Rate) }\end{array}$ & $\begin{array}{c}-.695[1] \\
(.535)\end{array}$ & $\begin{array}{r}-1.411 \quad[2] \\
(.909)\end{array}$ & $\begin{array}{l}-2.539^{* *} \\
(1.174)\end{array}$ \\
\hline $\begin{array}{c}\text { Sum of Current \& Lagged } \\
\Delta g \text { (Growth Rate) }\end{array}$ & $\begin{array}{cr}.077 & {[5]} \\
(1.489)\end{array}$ & ${ }_{(1.556)}^{1.154]}$ & $\begin{array}{ll}.695 & {[4]} \\
(1.698)\end{array}$ \\
\hline $\begin{array}{c}\text { Sum of Current \& Lagged } \\
\Delta \sigma_{P, M} \text { (Systematic Risk) }\end{array}$ & $\begin{array}{c}-5.384^{* * *}[3] \\
(1.115)\end{array}$ & $\begin{array}{c}-5.668^{* * *} \\
(1.184)\end{array}$ & $\begin{array}{c}-7.837^{* * *} \\
(1.773)\end{array}$ \\
\hline $\begin{array}{c}\text { Sum of Current \& Lagged } \\
\Delta \sigma \text { (Total Uncertainty) }\end{array}$ & $\begin{array}{c}1.649^{* * *}[3] \\
(.402)\end{array}$ & $\underset{(.432)}{1.650^{* * *}}[3]$ & $\begin{array}{r}3.076^{* * *} \\
(.656)\end{array}$ \\
\hline $\begin{array}{c}\text { Sum of Current, Lead \& } \\
\text { Lagged } \Delta C \text { (New Supply) }\end{array}$ & & $\begin{array}{ll}.160^{* *} & {[2]} \\
(.067) & \end{array}$ & $\begin{array}{l}.258^{*} \\
(.152)\end{array}$ \\
\hline$\rho$ & $\begin{array}{l}-.528^{* * *} \\
(.100)\end{array}$ & $\begin{array}{l}-.527^{* * *} \\
(.103)\end{array}$ & $\begin{array}{l}-.569^{* * *} \\
(.121)\end{array}$ \\
\hline $\mathrm{R}^{2}$ & .797 & .810 & .871 \\
\hline Adjusted- $\mathrm{R}^{2}$ & .742 & .751 & .778 \\
\hline Durbin-Watson & 1.80 & 1.74 & 1.67 \\
\hline
\end{tabular}

The dependent variable is the change in log of price of commercial real estate. $\rho$ is the estimate of the coefficient of first-order auto-correlation in the error term. Coefficient standard errors are in parentheses. ${ }^{*}$ indicates statistical significance at the 10 percent level, ${ }^{* *}$ indicates statistical significance at the 5 percent level and ${ }^{* * *}$ indicates statistical significance at the 1 percent level. The criteria used for determining current and lagged variables to include in the model is maximized adjusted- $\mathrm{R}^{2}$. The actual number of current and lagged (and possibly lead) variables included in model estimation is shown in brackets next to the coefficient estimate in each equation. Three different specifications are considered: one in which demand for commercial real estate is assumed to be completely elastic (column (1)), one in which demand is endogenously determined as a function of the reported current change in supply (column (2)), and one in which demand is endogenously determined as a function of the reported eight quarter lead in change in supply (column (3)).

The number of current, lagged and lead variables included in the model estimation are reported in brackets next to the coefficient estimate. As seen in column (1), numerous lags are included in the final model estimation for all five explanatory 
variables. In particular, six current and lagged variables are included for Net Rent, three for Interest Rate, and five for Income Growth, Systematic Risk and Total Uncertainty, respectively. This finding provides empirical support for the notion that, when frequent changes in the investment opportunity set occur and when market imperfections exist, analyzing past sequences of price determinants may improve asset price estimation.

Now consider the demand equation estimates seen in column (2) of Table 1, in which current (time $t$ ) supply is simultaneously determined with current (time $t$ ) asset price. Inclusion of the supply variable significantly improves the explanatory power of the model relative to the case in which supply is excluded from the specification. The supply variable enters the specification with a positive coefficient sign, but it is statistically insignificant at conventional levels. The economic interpretation of this estimate is that a one percentage point increase in Construction results in a 0.12 percent increase in Asset Price.

Although rather small economically, a positive supply-price relation is unexpected in the context of received theory. Capital constraints and imperfect substitutability among alternative investments suggest that asset demand curve may slope downward - but certainly not upward. Leasing market imperfections (use of shorterterm leases without the existence of a forward market in lease contracts) also imply a potential negative supply-price relation, since the supply variable increases may uniquely signal downward pressure on future rental rates. It is also worth noting at this point that the current and four of the lagged construction variables enter the model, including the eight-quarter lagged variable. This suggests that contemporaneous and historical supply data interact to assist investors in the process of asset price discovery.

Inclusion of the supply variable in this model has important effects on other asset price determinants. The Net Rent and the Systematic Risk variables become more important in the revised model specification, while the Interest Rate, Income Growth Rate and Total Uncertainty variables become less important. The systematic risk and total uncertainty variables are particularly affected. Systematic risk retains its negative coefficient sign but is now strongly statistically significant, whereas total uncertainty becomes statistically and economically unimportant. These revised estimates are now in line with predictions derived from conventional asset pricing theory, which emphasizes the role of systematic risk in the determination of asset price. Furthermore, an insignificant total uncertainty effect in combination with a positive supply variable coefficient fails to support the hypothesis that idiosyncratic risk is priced by risk-averse investors in equilibrium. In sum, what is clear from this estimation is that supply effects interact with other asset price determinants in ways that are unexplained by conventional asset pricing theory.

These interaction effects are amplified in the final model specification (as seen in column 3 of Table 1), in which the eight period construction lead is endogenous in the determination of asset market equilibrium. In this model the Supply variable enters the model with a positive and statistically significant coefficient, the Total 
Uncertainty variable becomes positive and statistically significant, the Systematic Risk variable assumes even greater economic importance, and the Interest Rate and Income Growth Rate variable coefficients become smaller and statistically insignificant. Also note that the Rent variable coefficient remains positive and is now statistically significant. Finally, the explanatory power of the model noticeably

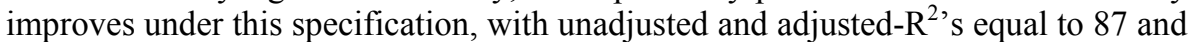
76 percent, respectively. The statistical significance of supply and the improved explanatory power of the model suggest that investors do become informed of investment decisions prior to the actual construction start announcement date, and that this information is useful to investors. Indeed, six of the eight possible leads in construction are included in model estimation.

As noted above, a positive and statistically significant supply variable coefficient is contrary to expectations. We can identify three potential explanations for the positive supply-asset price effect. The first relies on agglomerative interactions, in which complementary relations exist between properties to result in increasing returns to scale (Rauch, 1993), implying a true price elasticity effect.

A second explanation depends on market microstructure and incomplete information. Market equilibrium is such that supply is an information effect that shifts the entire demand curve, as opposed to changing its slope. One particularly appealing version of this approach is articulated by Grenadier (1999), which posits that bandwagon effects exist in which developers learn about asset demand by observing the actions of other developers. When better informed developers undertake (or defer) investment, other developers update their priors regarding real asset prices. Indeed, in the initial stages of an investment boom, market participants are predicted to frequently throw away their own prior assessments of asset price and jump onto the development bandwagon. The short-term information channel is therefore from supply change to asset price, which then feeds back to create positive momentum effects. These dynamics can occur independently of rent level, thus providing a clear structural role for a positive investment-price relation.

Grenadier's theory predicts that, throughout the early and middle stages of a development boom, supply will lead price as followers react to development decisions by informed investors. However, as the development cycle wears on, price catches up and even begins to lead development as investors overshoot the market equilibrium (i.e., they infer too much good news based on prior actions, and the market inevitably busts). Reference to panel A of Figure 2 provides visual evidence supporting this prediction. A significant development boom began in the U.S. in 1982 and peaked in 1986. During that time, construction clearly appears to lead price (prices do not peak until 1987). However, during and after the development bust of the late 1980's and early 1990's, prices began to move contemporaneously with construction and ultimately assumed a leading role.

An additional attractive feature of Grenadier's theory is that new investment is characteristically similar to trading volume as defined in the market microstructure literature. Trading volume is often specified as a correlate with unobservable 
aggregate trading demands, and hence is a useful metric in the price discovery process. There are several crucial differences between Grenadier's "development volume" measure and standard volume measures, however. Importantly, development has direct real effects, whereas the economic effects of secondary market trading are less direct. Market microstructure also differs markedly in commercial property markets as compared to exchange-traded financial asset markets. There are no dealers in commercial property markets to smooth inventory imbalances, and short selling is difficult to achieve. Interestingly, these market microstructure differences may serve to intensify positive short-term supply-price relations as compared to exchange-traded financial assets (see, for example, Diamond and Verrecchia, 1987; and Easley and O'Hara, 1992) for analysis of the effects of short-sale constraints on the price-volume relation).

A third hypothesis relies on financial market imperfections, where changes in real supply provide information to market participants as to the relative cost and availability of outside finance. As noted earlier, commercial real estate investors are often equity capital constrained, thus increasing their reliance on outside (typically debt) finance. Outside financing of built property and construction has traditionally originated from institutional sources. These intermediaries are often national in scope and are exposed to systematic market and regulatory effects that commonly impact investor capital costs and asset market liquidity. Furthermore, as Scharfstein and Stein (1990) point out, concern over reputational capital and the use of incentive contracts by financial institutions may also produce bandwagon effects that filter through to affect real asset markets. Consequently, when financial markets are prone to momentum effects, real investment activity may inform investors as to the cost and availability of outside finance, and thus affect the determination of asset price.

As noted earlier, the effect of Systematic Risk is enhanced when supply enters the model specification. Indeed, the performance of this variable is quite strong relative to standard asset pricing model estimation approaches, in which systematic risk is estimated as opposed to serving as an input variable. ${ }^{19}$ This suggests that investors may be more sensitive to second than first moments in their determination of asset prices (Merton, 1990, Ch.15). The importance of second moments is further highlighted by the statistical and economic significance of the Total Uncertainty variable, which now has a positive coefficient. The interpretation of this coefficient is that a 1 percentage point increase in total uncertainty (which generally ranges between 4 percent and 8 percent in levels in the data) results in a 6.7 percent (annualized) increase in asset price. A positive coefficient contradicts the investor under-diversification hypothesis, which posits that idiosyncratic risk negatively affects asset price.

What is responsible for this effect? First, it is clear that the supply and total uncertainty variables interact in important ways, as the sign of the uncertainty

19 In a separate specification we include a time dummy to control for the systematic effects of the 1987 stock market crash. This specification produced estimation results that were essentially identical to reported results. 
variable coefficient flips from negative and statistically significant when supply is excluded from the model to positive and statistically significant when supply leads are included in the demand model specification. One possibility is that an increase in uncertainty provides a strong signal of depressed investment further into the future, as predicted by the option model of irreversible investment (see Holland et. al., 2000; and Yoshida, 1999) for supportive empirical evidence). Total uncertainty could therefore proxy for shortcomings in rent and GDP measures, which generally fail to pick up longer-term cash flow growth implications. This interpretation augments the negative supply-price relation hypothesized early, in which total uncertainty is now informative as to longer-term income effects and supply plays a separate but complementary positive feedback role in the determination of asset price.

A second, related, explanation for this result is growth option value associated with investment in built commercial property (Childs et al., 1996; and Williams, 1997). Furthermore, redevelopment options become increasingly valuable as asset prices increase. Thus, positive feedback between supply and asset price may serve to intensify the relation between total uncertainty and asset price.

A third explanation for a positive price effect is that total uncertainty may reflect the rate of information arrival in commercial real estate asset markets. When asset price information is asymmetric or incomplete, an increase in the rate of revealed asset price information may increase asset prices because the disparity between informed and uninformed investors decreases (Wang, 1994) and because information acquisition costs decrease (Easterbrook and Fischel, 1999; and Childs et al., 2001).

Summarizing our results to this point, it is apparent that supply is an important determinant of asset price in U.S. commercial property markets. Indeed, our results indicate that severe model specification biases may result if the supply side of the market is excluded from asset demand estimation, as the more traditional asset demand variable coefficients change significantly depending on the model specification. Positive feedback between the supply and demand sides of the market thus provides a more complete explanation as to documented positive serial correlation in property and other real asset prices - results that follow from a reduced form model specification. Incorporation of supply in the model specification also appears to amplify the effects of risk, both systematic and idiosyncratic. Finally, lags (and leads in supply) are important in the determination of real asset price in all three model specifications, suggesting that analyzing sequences of variables improves inference regarding equilibrium asset price.

\subsubsection{Estimation Results: Japan}

Prior to analyzing model estimation results using Japanese data, it will be useful to briefly compare and contrast commercial property markets in the U.S. and Japan. In terms of size, Tokyo is the largest office market in the world, with 77 thousand square meters of space. Developed and undeveloped land in Japan is estimated to comprise 25 percent of total national assets, a much higher percentage than in the 
U.S. Japan is also a much more geographically concentrated than the U.S. According to a government survey, 28 percent of office space in Japan is located in metropolitan Tokyo. Approximately 70 percent of media and financial activity take place in Tokyo. There is nothing comparable to this in the U.S. Close institutional arrangements between groups of financial and industrial firms (the Keiretsu) have historically coordinated resource allocation in Japan, including commercial real estate development, with more or less economic efficiency. More recently, it has been thought these close relations have delayed structural change and thus slowed Japan's economic recovery. Alternatively, financing and ownership of commercial real estate is much more dispersed in the U.S. Finally, it is worth noting that leasing structures differ in the two countries. Lease terms rarely exceed three years in Japan, whereas a range of three to ten years is typical in the U.S.

Table 2 displays the asset demand model estimates derived from the Japanese data. These results are broadly consistent with U.S. results in terms of coefficient signs and model explanatory power. Indeed, with the exception of the Income Growth Rate variable, all of the standard asset demand determinants are statistically significant and have the same coefficient sign as the U.S. estimates. Similarly, adding the supply variable improves the explanatory power of the model and results in a statistically significant positive coefficient value. In terms of relative economic importance (Japan versus the U.S., as seen by comparing column 3 in Table 2 to column 3 in Table 1), Rent, Interest Rate and Total Uncertainty result in larger statistically significant coefficients, whereas Systematic Risk is of approximately equal importance and the Supply variable is of slightly less economic importance (although it is more important in the other model of endogenous supply as seen in column 2).

Estimation results suggest that new investment provides valuable information to investors, independent of income and other effects. When considering possible explanations for this finding, we note that agglomeration effects (provided they are relevant) should be more important in a country with highly concentrated urban areas. The lower comparative strength of the supply-asset price relation in Japan does not, therefore, provide additional support for the agglomeration hypothesis. ${ }^{20}$ The same might be said for the development bandwagon theory of Grenedier (1999) although information spillovers may have a strong systematic component when noisy demand conditions result from a combination of macroeconomic and idiosyncratic factors. Reference to panel A of Figure 3 shows that, consistent with predictions of the development bandwagon model, supply led price during the development boom of the early 1980's, only then to have price overtake and lead supply as the market finally peaked and busted in the 1990's. Consistent coefficient estimates across countries perhaps most favors the financial market imperfection hypothesis, which relies on economy-wide information/liquidity effects that channel from the financial to the real sector. A related effect is based on close business relations between financial and industrial firms within a Keiretsu, thus intensifying

20 It may be that increasing returns to scale have previously been realized due to already high levels of agglomeration, thus reducing marginal effects in recent time series. 
financial accelerator and debt-collateral cycle effects (Bernanke et al., 1996; and Kiyotaki and Moore, 1999).

As with U.S. estimates, systematic risk and total uncertainty effects are amplified when leads in supply are incorporated into model estimation. Total uncertainty is particularly effected, where it is estimated that a one percentage point increase in that measure results in a 12 percent annualized increase in asset price. This finding is consistent with the new development channel effect hypothesized earlier, in which an increase in total uncertainty signals less development (with a lag) and thus higher asset prices. Shorter lease terms and a more concentrated urban environment in Japan also imply increased sensitivity of asset price to total uncertainty, which is consistent with the comparative estimation results. An alternative hypothesis considered earlier, which relies on the rate of information arrival in an incomplete or asymmetric information environment, is most compelling when the distribution of asset value information is more widely varied. This may indeed be the case, as Japan is known for its relatively weak audit and information disclosure standards.

Structural relations in real asset markets require a modified interpretation of standard risk measures. Because returns to investment in income-producing commercial real estate do not conform to standard random walk assumptions, one cannot simply use historical time series (or reverse-filtered sequences) of prices to determine total uncertainty and systematic risk measures. One must first remove the predictable component of asset return, and then examine the residual errors. A strong structural component to real asset price may explain why conventional financial asset pricing models perform poorly in a real asset market setting and why there is much confusion and controversy surrounding the true risk underlying real asset prices (see, e.g., Lai and Wang, 1998; and Childs et. al., 2002).

Other findings generally conform to expectations. The real rate of interest has the anticipated negative effect on price, although the strength of the relation is weaker than one might expect. This may be due to informational effects embedded in other explanatory variables and short-term dislocations in real interest rates and asset prices that occurred during our sample period (especially during the oil crises of the mid-1970's). The income growth rate variable exerts perhaps the weakest economic effect of all demand determinants in our estimates. This may be due to short-run GDP growth providing an imperfect proxy of expected cash flow growth in property markets. Finally, systematic risk performs as expected and is quite important both statistically and economically. This is contrast to more conventional empirical tests of financial asset prices, where systematic risk as estimated within the model often has little predictive power.

Lastly note that, consistent with U.S. results, numerous lagged (and lead) values enter into the final model specification for all demand determinants (see column 3 ). For example, eight of nine possible rent values are included in the final model specification, and seven of the eight possible lead supply values make the cut (in which 12 lead-lag supply values are included all together). As noted earlier, changing investment opportunities and market imperfections may explain this 
outcome, thus providing justification for analyzing past sequences of price determinants in real asset markets.

Altogether, with some minor discrepancies, comparative results are remarkably similar between Japan and the U.S. A positive and statistically significant supplyasset price relation is robust across countries, suggesting an independent role for supply effects in the determination of real asset prices. Indeed, our results provide insight into a well known and puzzling phenomenon in commercial property markets: that observed price-earnings ratios are pro-cyclical in supply (with a short lag), whereas theory suggests that capitalization rates should be counter-cyclical (Williams, 1997; and Wheaton, 1999). Our results show that positive feedback between asset price and development inflates price-earnings ratios in boom markets and depresses them in bust markets. This effect is intensified by a positive total uncertainty-price relation in boom markets, in which supply increases are often accompanied by greater volatility in asset price.

\section{Summary and Concluding Remarks}

We have empirically examined the demand for an important class of real assets income producing commercial real estate - across the U.S. and Japan over a period ranging from the early 1970's through the late 1990's. We have focused on the structural determinants of asset demand by specifying models that incorporate economic (space) market effects as well as real investment and financial market variables. Most significantly, we consider the possible, fully endogenous, effects of new construction on the equilibrium demand for assets. Furthermore, in the spirit of Merton (1973) and market microstructure models of financial asset prices (see, e.g., O'Hara, 1997), we examine the impact of past sequences of demand determinants on asset prices.

Our major findings are that real investment and asset price are positively related, and that incorporation of supply into model specification has important effects on other demand determinants - especially our risk measures. Positive feedback between asset price and real investment provides insight into paradoxical capitalization ratesupply relations as well as boom and bust cycles observed in many real asset markets. Potential underlying causes for this outcome are specifically considered, including agglomeration economies (Rauch, 1993; and Cooper, 1999), development bandwagon effects (Grenadier, 1999) and financial market imperfections that lead to the over and under-supply of liquidity in real asset markets.

Investment and risk measures are found to interact and to exert complementary effects on asset prices. Most significantly, we find that idiosyncratic risk is positively related to asset price and that the economic importance of this effect grows when supply effects are fully endogenized into the model. Longer-term supply implications, redevelopment option value and the effects of information arrival are considered as possible explanations for this result. 
Numerous leads and lags are included in final demand equation specifications. The lead-lag structure of asset market demand suggests that, as hypothesized, analysis of past sequences of price determinants is useful when inferring current asset price.

Our findings have several related implications for the specification of pricing models in real asset markets. First, our results suggest that the structure of the real asset market should not be ignored in model specification. Doing so amounts to specifying a reduced form with the potential for severe bias in the estimation of asset pricing factor loadings. Wheaton (1990), Williams (1995) and Grenadier (1999) are important first steps in the articulation of "real" capital asset pricing models. Second, as originally suggested by Merton (1973), our results suggest an important role for second moments in the determination of asset prices. A similar issue is the measurement and interpretation of risk and uncertainty when there is a structural component to asset price. Simple analysis of historical time series of transactionbased asset prices will typically result in estimates of total uncertainty that are biased upward and market covariance measures that are biased towards zero.

Analysis in this paper is largely exploratory, and perhaps raises more questions that it answers. Unresolved issues include sorting out the underlying causes of positive feedback between asset price and real investment, as well as identifying what is behind the positive total uncertainty-asset price relation. Additional real asset market microstructure theory and data would also aid in more precise model specification and interpretation as to interaction and lead-lag effects as they relate to demand. For example, it is yet unclear whether innovations to the investment opportunity set or information disparity, or both or neither, underlie the lead-lag structure of our model estimation.

\section{Acknowledgment}

We wish to thank seminar and conference participants from the Asian Real Estate Society, European Real Estate Society, University of Texas - Austin, and University of Wisconsin - Madison for their helpful comments.

\section{References}

Bernanke, Ben, Mark Gertler, and Simon Gilchrist (1996). The Financial Accelerator and the Flight to Quality. Review of Economics and Statistics, 78, 1-15.

Childs, Paul D., Timothy J. Riddiough and Alex J. Triantis (1996). Mixed Uses and the Redevelopment Option. Real Estate Economics, 24, 317-339.

Childs, Paul D., Steven H. Ott and Timothy J. Riddiough (2001). Valuation and Information Acquisition Policy for Claims Written on Noisy Real Assets. Financial Management, 30, 45-75. 
Childs, Paul D., Steven H. Ott and Timothy J. Riddiough (2002). Optimal Valuation of Noisy Real Assets. Real Estate Economics, 30, 415-443.

Cooper, Russell W. (1999). Coordination Games: Complementarities and Macroeconomics. Cambridge University Press. Cambridge, UK.

Cornell, Bradford (1999). Risk, Duration and Capital Budgeting: New Evidence on Some Old Questions. Journal of Business, 72, 183-200.

Diamond, Douglas W. and Robert E. Verrecchia (1987). Constraints on Shortselling and Asset Price Adjustment to Private Information. Journal of Financial Economics, 18, 277-311.

Dickey, D.A. and W.F. Fuller (1979). Distribution of the Estimates for AutoRegressive Time Series With a Unit Root. Journal of the American Statistical Association, 74, 427-431.

Dickey, D.A. and W.F. Fuller (1981). Likelihood Ratio Statistics for Autoregressive Time Series With a Unit Root. Econometrica, 49, 1057-1072.

DiPasquale, Denise and William C. Wheaton. (1996). Urban Economics and Real Estate Markets. Prentice-Hall, Inc. Englewood Cliffs, NJ. USA.

Easley, Donald and Maureen O’Hara (1992). Time and the Process of Security Price Adjustmet. Journal of Finance, 47, 577-606.

Easterbrook, Frank H. and Daniel R. Fischel (1998). The Economic Structure of Corporate Law. Harvard University Press. Cambridge, MA. USA.

Eichholtz, Piet M.A. (1997). A Long-Run House Price Index: The Herengrecht Index, 1628-1973. Real Estate Economics, 25, 175-192.

Engle R.F. and C.W.J. Granger (1987). Co-integration and Error Correction Representation, Estimation and Testing. Econometrica, 55, 251-276.

Grenadier, Steven R. (1999). Information Revelation Through Option Exercise. The Review of Financial Studies, 12, 95-129.

Heaton, John and Deborah Lucas (2000). Portfolio Choice and Asset Prices: The Importance of Entrepreneurial Risk. Journal of Finance, 55, 1163-1198.

Holland, A. Steven, Steven H. Ott and Timothy J. Riddiough (2000). The Role of Uncertainty in Investment: An Examination of Competing Investment Models Using Commercial Real Estate Data. Real Estate Economics, 28, 33-64. 
Jorgenson, David (1963). Capital Theory and Investment Behavior. American Economic Review, 53, 247-259.

Kiyotaki, Nobuhiro and John Moore (1999). Credit Cycles. Journal of Political Economy, 105, 211-248.

Kindleberger, Charles P. (1996). Manias, Panics, and Crashes. John Wiley and Sons, Inc. New York, NY. USA.

Lai, Tsong-Yue and Ko Wang (1998). Appraisal Smoothing: The Other Side of the Story. Real Estate Economics, 26, 511-535.

Mayer, Christopher J. and C. Tsuriel Somerville (2000). Land Use Regulation and New Construction. Regional Science and Urban Economics, 30, 639-662.

Merton, Robert C. (1969). Lifetime Portfolio Selection Under Uncertainty: The Continuous-Time Case. Review of Economics and Statistics, 51, 247-257.

$\overline{\mathbf{4 1}, 867-887 .}$

(1973). An Intertemporal Capital Asset Pricing Model. Econometrica (1990). Continuous-Time Finance. Basil-Blackwell, Inc. Cambridge, MA. USA.

Morris, Charles P. (1999). Money, Greed and Risk: Why Financial Crises and Crashes Happen. Random House, New York, NY. USA.

O’Hara, Maureen (1997). Market Microstructure Theory. Blackwell Publishers Corp. Malden, MA. USA.

Quan, Daniel and Sheridan Titman (1999). Do Real Estate Prices and Stock Prices Move Together? An International Analysis. Real Estate Economics, 27, 183-207.

Rauch, James E. (1993). Does History Matter Only When It Matters Only a Little? The Case of City-Industry Location. Quarterly Journal of Economics, 108, 843-867.

Ross, Stephen A. (1976). The Arbitrage Theory of Capital Asset Pricing. Journal of Economic Theory, 13, 341-360.

Scharfstein, David S. and Jeremy C. Stein (1990). Herd behavior and investment. American Economic Review, 80, 465-479.

Stock, J.H. and M.W. Watson (1988). Variable Trends in Economic Time Series. Journal of Economic Perspectives, 24, 147-174.

Strange, William and Duo Tang (2000). Determinants of REIT Returns: 1978-1998. Masters Thesis. MIT. 
Stulz, Rene (1999). International Portfolio Flow and Security Markets. Working Paper. Ohio State University.

Tobin, James (1969). A General Equilibrium Approach to Monetary Theory. Journal of Money, Credit and Banking, 1, 15-29.

Wang, Jiang (1994). A Model of Competitive Stock Trading Volume. Journal of Political Economy, 102, 127-168.

Wheaton, William C. (1987). The Cyclic Behavior of the National Office Market. Journal of the American Real Estate and Urban Economics Association, 15, 281299.

(1990). Vacancy, Search and Prices in a Housing Market Matching Model. Journal of Political Economy, 98, 1270-92.

(1999). Real Estate "Cycles": Some Fundamentals. Real Estate Economics, 27, 209-230.

Wheaton, W.C. and Raymond G. Torto (1990). An Investment Model of the Demand and Supply for Industrial Real Estate. Journal of the American Real Estate and Urban Economics Association, 18, 530-547.

Williams, Jospeph T. (1993). Equilibrium and options on real assets. Review of Financial Studies, 6, 825-850.

(1995). Pricing Real Assets With Costly Search. Review of Financial Studies, 8, 55-90.

(1997). Redevelopment of Real Assets. Real Estate Economics, 25, $387-407$.

Yoshida, Jiro (1999). Effects of Uncertainty on the Investment Decision: An Examination of the Option-Based Investment Model Using Japanese Real Estate Data. Masters Thesis. MIT. 